This manuscript has been authored by UT-Battelle, LLC under Contract No. DE-AC0500OR22725 with the U.S. Department of Energy. The United States Government retains and the publisher, by accepting the article for publication, acknowledges that the United States Government retains a non-exclusive, paid-up, irrevocable, world-wide license to publish or reproduce the published form of this manuscript, or allow others to do so, for United States Government purposes. The Department of Energy will provide public access to these results of federally sponsored research in accordance with the DOE Public Access Plan(http://energy.gov/downloads/doe-public-access-plan).

\title{
Corrosion of Stainless Steels in the Riser During Co-Processing of Bio-Oils in a Fluid Catalytic Cracking Pilot Plant
}

a, ${ }^{*}$ M.P. Brady, ${ }^{\mathrm{a} J}$ J.R. Keiser, ${ }^{\mathrm{a} D}$ D.N. Leonard, ${ }^{\mathrm{b}}$ A.H. Zacher, ${ }^{\mathrm{c}}$ K. J. Bryden, ${ }^{\mathrm{c}}$ G.D. Weatherbee

${ }^{a}$ Oak Ridge National Laboratory, Oak Ridge, TN 37831-6156 USA

${ }^{\mathrm{b}}$ Pacific Northwest National Laboratory, PO Box 999, Richland, WA 99352 USA

${ }^{c}$ Grace Catalysts Technologies, 7500 Grace Drive, Columbia, MD 21044 USA

*corresponding author bradymp@ornl.gov

MS 6156, Oak Ridge National Laboratory, Oak Ridge, TN USA 37831-6156

TEL: 8655745153

\begin{abstract}
Co-processing of bio-oils with conventional petroleum-based feedstocks is an attractive initial option to make use of renewable biomass as a fuel source while leveraging existing refinery infrastructures. However, bio-oils and their processing intermediates have high concentrations of organic oxygenates, which, among their other negative qualities, can result in increased corrosion issues. A range of stainless steel alloys (409, 410, 304L, 316L, 317L, and 201) was exposed at the base of the riser in a fluid catalytic cracking pilot plant while co-processing vacuum gas oil with pine-derived pyrolysis bio-oils that had been catalytically hydrodeoxygenated to $\sim 2$ to $28 \%$ oxygen. A catalyst temperature of $704^{\circ} \mathrm{C}$, a reaction exit temperature of $520^{\circ} \mathrm{C}$, and total co-processing run times of $57-75 \mathrm{~h}$ were studied. External oxide scaling 5-30 micrometers thick and internal attack 1-5 micrometers deep were observed in these short-duration exposures. The greatest extent of internal attack was observed for co-processing
\end{abstract}


with the least stabilized bio-oil, and more so for types 409, 410, 304L, 316L, 317L stainless steel than for type 201. The internal attack involved porous Cr-rich oxide formation, associated with local Ni-metal enrichment and S-rich nanoparticles, primarily containing $\mathrm{Cr}$ or $\mathrm{Mn}$. Implications for alloy selection and corrosion are discussed.

Keywords: stainless steel; corrosion; bio-oil, biomass; co-processing; fluid catalytic cracking

\subsection{Introduction}

Biomass is being pursued as a sustainable and renewable energy source of liquid bio-fuels, encompassing a spectrum of applications from both biomass-fired boilers to biomass-derived liquid transportation fuels [1-3]. Thermochemical pyrolysis of biomass to produce bio-oil, and subsequent upgrading to produce liquid transportation bio-fuels such as gasoline, jet fuel, and diesel is of particular recent interest due to the reliance of transportation on liquid fuels [3-11]. Due to the compositional differences between petroleum and bio-oil, production of liquid transportation fuels from bio-oil is envisioned as a separate processing pathway that enters the hydrocarbon economy at the point of fuel blending, requiring separate capital investment that does not leverage existing refinery infrastructure [3-11]. In response, researchers have considered the requirements that must be met to co-process bio-oils in the refinery environment rather than at the point of blending [7]. However biomass-derived pyrolysis oils and their processing intermediates contain significant concentrations of organic oxygenates, including carboxylic acids (formic, acetic, etc.), which reduce the storage stability of the pyrolysis oil and result in the formation of gums and deposits when the pyrolysis oil is mixed with petroleum based feedstocks. In addition to these negative qualities, the organic oxygenates in biomass- 
derived pyrolysis oils can cause increased corrosion issues in the materials used for storage, transport, use and conversion to fuel [10-13].

Fluid catalytic cracking (FCC) is one of the primary hydrocarbon conversion units in modern petroleum refinieries. It converts the higher molecular weight components of petroleum, such as vacuum gas oil (VGO), to gasoline, light fuel oil and petrochemical feedstocks such as propylene and butylene $[14,15,16]$. In the United States, FCC and the alkylation unit it supplies produce about 50\% of the gasoline pool in most refineries [17]. Co-processing of bio-oils with conventional petroleum-based products such as VGO is an attractive initial option to make use of renewable biomass as a fuel source, while leveraging existing refinery infrastructure [14-15, 1824]. However, the use of untreated bio-oils as a co-processing feedstock results in processing difficulties in the FCC due to plugging from increased coke deposition [25-28]. Hydrotreating can be used to produce higher quality bio-oil intermediates more compatible with existing refinery infrastructure, with a further benefit of lower oxygenate content to potentially reduce corrosion issues, although hydrotreating also increases cost [25-27].

Development and optimization of bio-oil co-processing is an active area of study focusing on many technical challenges [e.g. 14-15, 18-24], but little research has been pursued of potential impacts of co-processing with bio-oils on the corrosion of materials of construction used in the FCC unit. One area of the FCC unit that can experience corrosion is the riser reactor. At the base of the riser reactor, hot catalyst from the regenerator (typically between 640 and $760^{\circ} \mathrm{C}$ ) contacts the feedstock. This vaporizes the feed, and the mixture of catalyst and petroleum feed travels up the riser. Cracking occurs in the riser section and transport takes between 2 and 10 
seconds, depending on unit design [16] Most riser designs are "cold-wall" where the pressure boundary of the vessel is carbon steel, with a several centimeter layer of refractory placed on top of the carbon steel to reduce its temperature and prevent abrasion from the catalyst. Stainless steel alloys are used for feed nozzles, the mesh that holds the refractory and some of the internal components of the riser $[29,30]$. Multiple modes of corrosion attack are potentially encountered in conventional FCC units, including oxidation, sulfidation, carburization, etc. [29-38]. Such phenomena have been studied from both an applied/materials selection/durability viewpoint [2933] and a fundamental mechanistic perspective [32-38].

The present work took advantage of a multi-institution study by W.R. Grace, Technical Research Centre of Finland, Tesoro, Aston University, Pacific Northwest National Laboratory, Los Alamos National Laboratory, and Oak Ridge National Laboratory devoted to co-processing optimization of VGO and pyrolysis bio-oils to explore the impacts of the bio-oil constituent on the corrosion behavior of stainless steels [39]. A series of stainless steel alloy test samples were placed at the base of a FCC pilot plant riser and exposed during a series of short-term (57-75 h) co-processing campaigns using VGO and pyrolysis bio-oil that had been catalytically hydrotreated to varying degrees of hydrodeoxygenation (total run times of 75-135 $\mathrm{h}$ including initial FCC pilot plant run startup using 100\% VGO). These exposures were too short in duration to quantitatively assess corrosion resistance of the alloys in the co-processing environment, particularly from a plant-durability component lifetime perspective. Rather the goal of this work was to gain insight into the initial stages of corrosion and the mechanism of attack, with an emphasis on advanced characterization of the scale/subscale microstructure features for several different types of stainless steels in the co-processing environment. 


\subsection{Materials and Methods}

A range of stainless steel alloys was exposed at the base of the riser reactor of a Grace DCR (Davison Circulating Riser) FCC pilot plant (Figure Supplemental 1). The DCR is a continuous circulating pilot plant consisting of a riser reactor, stripper and regenerator; the same vessels present in a commercial FCC unit. Typical feed rates are $1 \mathrm{~kg} / \mathrm{hr}$ and typical catalyst to oil ratios are between 6 and 12. A detailed description of the pilot plant can be found in references 28 and 40. Co-processing of VGO with 3 to 10 weight \% (wt.\%) pine-derived pyrolysis bio-oils with different degrees of hydrodeoxygentation (HDO) ( 2 to 28 wt. \% oxygen) was done in the FCC pilot plant. For the majority of the co-processing work, a mid-continent VGO with a specific gravity of $0.9059\left(\right.$ at $16^{\circ} \mathrm{C}$ ) and a sulfur content of $0.35 \mathrm{wt} \%$ was primarily used (nitrogen content was 0.14 wt. \%, oxygen content was $0.24-0.27$ wt.\%). For two short experiments coprocessing the severely hydrotreated bio-oil, two additional VGOs were used, VGO2 with a specific gravity of 0.927 (at $16^{\circ} \mathrm{C}$ ) and sulfur content of $0.93 \mathrm{wt} . \%$, and VGO3 with a specific gravity of $0.927\left(\right.$ at $\left.16^{\circ} \mathrm{C}\right)$ and sulfur content of $1.41 \mathrm{wt} . \%$. The catalyst used was a conventional zeolite Y (faujasite) containing equilibrium commercial fluid cracking catalyst obtained from a refinery processing a low-metals vacuum gas oil. The catalyst had less than 100 parts per million mass each of contaminant nickel and vanadium deposited by the feedstock

\section{$\underline{2.1 \text { Alloys }}$}

Up to five alloys were exposed per FCC pilot plant co-processing run, representing a range of alloy content (Cr, Ni, Mn, Mo levels), cost, and stainless steel class (ferritic and austenitic). Analyzed alloy compositions are shown in Table 1. 
Table 1- Analyzed compositions of alloys (wt.\%) as determined by inductively coupled plasma optical emission spectroscopy and combustion techniques combined with infrared analysis (listed in approximate order of least to most expensive). The 409 and 410 are ferritic grades, and the remaining alloys are austenitic. Metallic impurities $<0.01 \mathrm{wt} . \%$ not reported.

\begin{tabular}{|c|c|c|c|c|c|c|c|c|}
\hline Alloy & $\mathrm{Fe}$ & $\mathrm{Ni}$ & $\mathrm{Cr}$ & Mo & $\mathrm{Mn}$ & $\mathrm{Si}$ & $\mathrm{C}$ & other \\
\hline 409 & 87.56 & 0.14 & 11.36 & 0.01 & 0.13 & 0.49 & 0.01 & $\begin{array}{l}0.007 \mathrm{~N}, \\
0.01 \mathrm{Cu}, \\
0.14 \mathrm{Ti}, \\
<0.001 \mathrm{~S}\end{array}$ \\
\hline 410 & 86.49 & 0.15 & 12.05 & 0.03 & 0.43 & 0.44 & 0.14 & $\begin{array}{l}0.014 \mathrm{~N}, \\
0.12 \mathrm{Cu}, \\
0.07 \mathrm{~V} \\
0.03 \mathrm{Nb} \\
0.001 \mathrm{~S}\end{array}$ \\
\hline 201 & 70.84 & 4.46 & 15.9 & 0.27 & 6.97 & 0.48 & 0.078 & $\begin{array}{l}0.068 \mathrm{~N}, \\
0.08 \mathrm{Co}, \\
0.71 \mathrm{Cu}, \\
0.05 \mathrm{~V}, \\
0.02 \mathrm{~W}, \\
0.01 \mathrm{Ti}, \mathrm{Nb}, \\
\mathrm{Sn}, \\
0.001 \mathrm{~S}\end{array}$ \\
\hline $304 \mathrm{~L}$ & 71.61 & 8.06 & 18.07 & 0.06 & 1.29 & 0.54 & 0.024 & $\begin{array}{l}0.064 \mathrm{~N}, \\
0.03 \mathrm{Co}, \\
0.01 \mathrm{Cu}, \mathrm{Ti}, \\
0.001 \mathrm{~S}\end{array}$ \\
\hline $316 \mathrm{~L}$ & 69.21 & 10.11 & 16.6 & 2.0 & 1.12 & 0.52 & 0.022 & $\begin{array}{l}0.041 \mathrm{~N} \\
0.22 \mathrm{Cu} \\
0.09 \mathrm{~V} \\
0.01 \mathrm{Ti} \\
0.001 \mathrm{~S}\end{array}$ \\
\hline $317 \mathrm{~L}$ & 62.29 & 14.24 & 17.74 & 2.97 & 1.69 & 0.56 & 0.022 & $\begin{array}{l}0.026 \mathrm{~N}, \\
0.23 \mathrm{Co}, \\
0.11 \mathrm{Cu}, \\
0.04 \mathrm{~V}, \\
0.01 \mathrm{Ti}, \\
0.007 \mathrm{~S}\end{array}$ \\
\hline
\end{tabular}

\subsection{FCC Pilot Plant Exposures}

The corrosion test samples consisted of $17.8 \mathrm{~cm}$ long by $0.64 \mathrm{~cm}$ wide alloy strips cut from sheet material, thicknesses varied from 1.1 to $1.8 \mathrm{~mm}$ depending on the alloy (mill surface finish retained in order to expose "real" industrial alloy surfaces). They were welded to $\sim 23-30 \mathrm{~cm}$ long 
weld wire pieces that were used to vertically positon the test samples in the mixing chamber at the base of the riser at approximately $60^{\circ}$ spacing (Figure S1), which permitted exposure of up to 5 samples per co-processing run. The remaining one sixth of the FCC pilot plant mixing chamber was committed to the line introducing the hot catalyst from the regenerator to the mixing chamber. In the mixing chamber at the base of the riser, the mixture of VGO and bio-oil was introduced through a nozzle (using steam for atomization) and contacted with hot catalyst. The catalyst and vaporized oil then traveled up the riser. This location was chosen since it is expected to experience the greatest level of hot oxygen containing acids from the bio-oil constituent.

The FCC pilot plant co-processing run details are provided in Table 2. Run hours for $100 \%$ VGO and for the VGO/bio-oil blends are reported for each campaign. The $100 \%$ VGO was run while starting up the unit each day and for certain control runs. For the three bio-oil campaigns, the time on $100 \%$ VGO ranged from 54 to $60 \mathrm{~h}$ and the time running the VGO/bio-oil blends ranged from $57 \mathrm{~h}$ for the mildly stabilized bio oil to 74 to $75 \mathrm{~h}$ for the moderately and severely stabilized bio-oils. The mildly stabilized bio-oil has fewer operating hours since there were many more operating difficulties with this feedstock. The length of the control campaign with $100 \%$ VGO was $75 \mathrm{~h}$.

Pine-derived bio-oil was produced by fast pyrolysis at VTT Technical Research Centre of Finland in the $20 \mathrm{~kg} / \mathrm{h}$ Process Development Unit (PDU), a circulating fluidized bed operating at $460-480^{\circ} \mathrm{C}[39,41]$. The pine pyrolysis oils were then hydrotreated to varying degrees in the $400 \mathrm{ml}$ and $800 \mathrm{ml}$ pilot scale dual bed catalytic hydrotreater unit at Pacific Northwest National 
Laboratory [27, 41, 42]. The FCC pilot plant co-processing was performed with VGO, using a catalyst temperature of $704^{\circ} \mathrm{C}$, a reaction exit temperature of $520^{\circ} \mathrm{C}$, and total co-processing run times in the range of 57-75 $\mathrm{h}$ (Table 2). The temperature at the mix zone where the corrosion coupons were located ranged between 525 and $550^{\circ} \mathrm{C}$ during coprocessing. Processing was performed similarly to reference 28 .

Table 2: Overview of FCC pilot plant co-processing run details. The raw pine oil feedstock contained $37.6 \%$ oxygen (the raw source pine dust contained $<0.01 \mathrm{wt}$ \% sulfur), and the VGO contained $0.24-0.24 \mathrm{wt} . \%$ oxygen.

\begin{tabular}{|c|c|c|c|c|c|c|c|}
\hline \multirow{2}{*}{$\begin{array}{l}\text { Run details: } \\
\text { degree of } \\
\text { catalytic } \\
\text { hydrotreating }\end{array}$} & \multirow{2}{*}{$\begin{array}{l}\text { Percent } \\
\text { Oxygen in } \\
\text { bio-oil (dry } \\
\text { basis) }\end{array}$} & \multirow{2}{*}{$\begin{array}{l}\text { Maximum } \\
\text { VGO feed } \\
\text { preheat } \\
\text { temperature } \\
\text { without } \\
\text { nozzle } \\
\text { plugging }\end{array}$} & \multirow{2}{*}{$\begin{array}{l}\text { Maximum } \\
\text { percentage } \\
\text { pine } \\
\text { pyrolysis } \\
\text { oil } \\
\text { coprocessed }\end{array}$} & \multicolumn{3}{|c|}{\begin{tabular}{|l|} 
Run Hours for Different \\
Feedstocks
\end{tabular}} & \multirow[t]{2}{*}{$\begin{array}{l}\text { Alloys } \\
\text { Studied }\end{array}$} \\
\hline & & & & \begin{tabular}{|l|} 
Run \\
Hours \\
$100 \%$ \\
VGO \\
\end{tabular} & $\begin{array}{l}\text { Run } \\
\text { Hours } \\
\text { VGO/bio- } \\
\text { oil blends }\end{array}$ & $\begin{array}{l}\text { Total } \\
\text { Run } \\
\text { Hours }\end{array}$ & \\
\hline $\begin{array}{l}\text { Mildly- } \\
\text { stabilized } \\
\text { pine oil }\end{array}$ & 28.1 & $\sim 93^{\circ} \mathrm{C}$ & $\begin{array}{l}\text { up to } 3 \text { wt } \% \\
\text { with } \\
\text { difficulty }\end{array}$ & 54 & 57 & 111 & $\begin{array}{l}410, \\
201, \\
304 \mathrm{~L}, \\
316 \mathrm{~L}\end{array}$ \\
\hline $\begin{array}{l}\text { Moderately- } \\
\text { stabilized } \\
\text { pine oil }\end{array}$ & 11.2 & $\begin{array}{l}\text { Up to } \\
370^{\circ} \mathrm{C}\end{array}$ & $10 \mathrm{wt} \%$ & 55 & 74 & 129 & $\begin{array}{l}201, \\
304 \mathrm{~L}, \\
316 \mathrm{~L}, \\
317 \mathrm{~L}\end{array}$ \\
\hline $\begin{array}{l}\text { Severely- } \\
\text { stabilized } \\
\text { pine oil }\end{array}$ & 2.1 & $\begin{array}{l}\text { Up to } \\
370^{\circ} \mathrm{C}\end{array}$ & $10 \mathrm{wt} \%$ & 60 & 75 & 135 & $\begin{array}{l}410, \\
201, \\
304 \mathrm{~L}, \\
316 \mathrm{~L}\end{array}$ \\
\hline $\begin{array}{l}\text { Control } \\
100 \% \text { VGO }\end{array}$ & & $\begin{array}{l}\text { Up to } \\
370^{\circ} \mathrm{C}\end{array}$ & $\mathrm{n} / \mathrm{a}$ & 75 & 0 & 75 & $\begin{array}{l}409, \\
201, \\
304 \mathrm{~L}, \\
316 \mathrm{~L}\end{array}$ \\
\hline
\end{tabular}

Note 1: For the mildly stabilized pine oil, moderately stabilized pine oil and the control case, the VGO feedstock was always mid-Continent VGO. For the campaign with the severely stabilized pine oil, the mid-continent VGO was the primary feedstock. VGO2 was used for 11 hours of the pure VGO portion and 9 hours of the VGO/bio-oil blend portion. VGO3 was used for 12 hours of the pure VGO portion and 8 hours of the VGO/bio-oil portion. 


\subsection{Post-Exposure Characterization}

Five cross-sections were prepared and analyzed per test alloy, located at $\sim 3.2,6.4,9.5,12.7$, and $16 \mathrm{~cm}$ along the test bar as measured from the lower end of the bar. The cross-sections were prepared by standard metallographic techniques using non-aqueous polishing media in an effort to better retain any aqueous soluble corrosion products (particularly chlorides) which may have formed. Characterization was primarily accomplished using light optical microscopy and scanning electron microscopy (SEM) equipped with energy dispersive x-ray analysis (EDS) (Hitachi 3400). Selected samples were also analyzed by electron probe microanalysis (EPMA) with wavelength dispersive techniques (JEOL 8200), and cross-section scanning transmission electron microscopy (STEM) (Hitachi HF3300 TEM STEM equipped with a Bruker SDD 6T-60 X-ray detector), using focused ion beam (FIB) milling lift-out (Hitachi NB5000 FIB/SEM) to prepare local cross-section regions for analysis.

\subsection{Results and Discussion}

\subsection{Cross-Section SEM Analysis}

Cross-section backscattered mode SEM images of alloy test samples from the three coprocessing runs using mild, moderate, and severe hydrodeoxygentation stabilized pyrolysis biooils (Table 2) and a control 100\% VGO run are shown in Figures 1-4 (preliminary characterization findings for the co-processing run with the mildly-stabilized bio-oil were reported in conference proceedings [43-45]). The micrographs presented in Figures 1-4 typically represent the locations where the greatest extent of oxide scale thickness and internal attack were observed. It is important to note that the oxide scales were loosely adherent in some locations, and that local oxide spallation in some areas may yield scales apparently thinner than the actual extent of corrosive attack experienced by the test samples. Such scale loss is likely, for example, 
in Fig. 2a, c for 201 and 316L stainless steel samples from the moderately-stabilized bio-oil coprocessing run. Given the welding and handling required to place the test samples for in-situ FCC pilot plant exposure and remove them from the pilot plant post-exposure, as well as the potentially erosive environment of a fluidized bed, it was not viable to use mass change to quantitatively assess the extent of corrosion.

The FCC pilot plant runs were on the order of 75-135 h (Table 2, including both co-processing and initial $100 \%$ VGO startup), which resulted in only a moderate extent of corrosion (scales generally on the order of $\sim 5-30$ micrometers maximum thickness observed and internal attack up to 1-5 micrometers deep, depending on the specific alloy and co-processing run condition). This extent of corrosion attack was not sufficient to make use of quantitative cross-section thickness measurements of intact metal lost, as the error range in such measurements is typically on the order of $\pm 10-20$ micrometers. However, the oxide scale and internal attack features observed in cross-sections still provide useful insights into the initial stages of corrosion and the corrosion attack mechanism as a function of alloy type and co-processing environment. Observations regarding the relative corrosion resistance of the alloys were possible in a qualitative manner based on morphological features observed over the entirety of the cross-sections by light microscopy and SEM techniques, in particular the nature and thickness of the oxide scale, the planarity of the oxide scale interfaces, and the extent of internal attack. Several trends were apparent:

1) The greatest extent of corrosion was observed in the co-processing run using the mildlystabilized bio-oil ( $28 \%$ O), (Table 2, Fig. 1 vs Figures 2-4). The co-processing runs using the 
moderately $(\sim 11 \%$ O) and severely stabilized $(\sim 2 \%$ O) bio-oil, and the 100\% VGO control run resulted in less extensive, generally comparable levels of corrosion.

2) Consistent with its low Cr content (Table 1), 409/410 stainless steels generally exhibited the thickest extent of oxide scale formation, suggesting the fastest corrosion rate among the alloys and FCC co-processing conditions evaluated (Figures 1-4).

3) The low Ni/high Mn 201 stainless steel (Table 1) generally exhibited the thinnest oxide scales and least extent of internal attack, suggesting greater initial corrosion resistance in the coprocessing run environments than the more costly, higher-Ni 304L, 316L, and 317L stainless steels.

The corrosion mode observed for the 409/410 stainless steel was primarily oxide scaling (e.g. Figure 1a). However, for the austenitic stainless steels, internal attack was also observed (e.g. Figures 1b, c, d). Selective inward corrosion penetration on the order of 1-5 micrometers depth was observed for $304 \mathrm{~L}$ and $316 \mathrm{~L}$ in the co-processing run using the mildly-stabilized bio-oil (Figures $1 \mathrm{c}, \mathrm{d}$ ). The internal attack was primarily associated with alloy grain boundaries for the 304L, but not for the 316L. Although internal attack was also observed in 201stainless steel (Figure 1b), the extent appeared qualitatively less than that observed for 304L and 316L. Prior work examining test sample exposures as well as operated components from a range of biomass pyrolysis related process environments observed a similar susceptibility of 304L and 316L stainless steels to internal attack, frequently along alloy grain boundary regions [43-46]. 
The alloys exposed in the moderately-stabilized (Figure 2), severely-stabilized (Figure 3) coprocessing runs, and the $100 \%$ VGO control run (Figure 4) showed comparable features of moderate scaling and minor degrees of internal attack (1 micrometer range). Type 317L stainless steel, which has moderately higher levels of $\mathrm{Cr}, \mathrm{Ni}$, and Mo additions (Table 1) but is also more costly, was included in the co-processing run using the moderately-stabilized bio-oil (Table 2, Figure 2d), but still showed similar susceptibility to scaling and internal attack to the 304L and 316L. To provide insight into the mechanism of corrosion as a function of alloy composition in the co-processing environment, detailed microstructural characterization by EPMA and STEM was pursued for the alloys from the mildly-stabilized co-processing run, which produced the greatest extent of corrosion.

\subsection{Cross-section EPMA and STEM Analysis}

Figures 5-8 show EPMA cross-section backscattered electron images and corresponding elemental maps for 410, 201, 304L, and 316L test samples, respectively, from the mildlystabilized bio-oil and VGO co-processing run (Table 2). In addition to oxide (O) formation, the presence of sulfur (S) was widely detected, both in the external oxide scale and particularly near the alloy-scale interface for all four alloys. For the 410 stainless steel, the oxide scale was Ferich, with minor amounts of $\mathrm{Cr}$ and $\mathrm{Si}$ also intermixed throughout (Figure 5). The oxide scale chemistry for the 201 stainless steel (Figure 6) was also Fe-rich, but with $\mathrm{Cr}$ and $\mathrm{Mn}$ intermixed throughout the inner and mid-scale regions. Some local regions of Ni-enrichment were observed at the alloy-scale interface, and were associated with S. 
The outer scale regions formed on the 304L and 316L were Fe-rich with a minor amount of Mn (Figures 7, 8). The inner scale regions on the 304L and 316L were enriched in $\mathrm{Cr}$ and $\mathrm{Si}$, typical of the oxidation of stainless steels [47, 48], although Fe was also present. Extensive local regions of $\mathrm{Ni}$ enrichment associated with $\mathrm{S}$ were observed at the alloy-scale interface for the 304L and 316L stainless steels (Figures 1, 7, and 8), to a greater extent compared to that observed for the 201 stainless steel (Figure 6). In these Ni-S rich regions, internal attack was evident at the interface between the local Ni-enrichment and the surrounding alloy. (As will be seen, STEM work in Figures 9-13 show that the local Ni-S observed in EPMA maps is not Ni-sulfide, but rather Ni-rich metal containing $\mathrm{Cr}, \mathrm{Mn}$ sulfide nanoparticles). Collectively, these findings indicated that continuous, exclusive chromia $\left(\mathrm{Cr}_{2} \mathrm{O}_{3}\right)$ scales were not formed in the co-processing environment. Instead, multi-layered Fe-rich oxide scales were formed, with increasing $\mathrm{Cr}$ content in the inner regions of the scale near the alloy-scale interface (higher $\mathrm{Cr}$ content is associated with more protective oxide scales).

The accumulated enrichment of $\mathrm{Ni}$ at the alloy-scale interface during corrosion is consistent with the Fe-rich oxide scales formed and the lower thermodynamic stability of Ni-oxide compared to that of the oxides of $\mathrm{Cr}, \mathrm{Fe}$ and $\mathrm{Mn}$ [49]. The enrichment of $\mathrm{Ni}$ and accompanying presence of $\mathrm{S}$ in this region, along with the associated internal oxidation has been reported for a range of biomass-induced corrosion conditions. Nickel enrichment near the metal scale interface, accompanied by S, was recently reported for TP $347 \mathrm{H} \mathrm{FG}$ austenitic stainless steel (similar $\mathrm{Cr}$ and Ni content to 304L and 316L of the present work) under conditions mimicking biomass firing, although it is important to note that attack was also associated with $\mathrm{K}$ and $\mathrm{Cl}$ species, which were not observed in the present work $[50,51]$. Enrichment of $\mathrm{Ni}$ associated with internal 
oxidation and sulfidation was also recently reported for a $316 \mathrm{~L}$ biomass pyrolysis tube component operated for several thousand hours [44].

To better understand this phenomenon, FIB lift-out of internal attack regions and STEM characterization was pursued. Figure 9 shows cross-section STEM analysis and elemental maps for 304L from the mildly-stabilized bio-oil and VGO co-processing run (Figure 7) at the alloyscale interface in the vicinity of a local area of Ni-enrichment/internal alloy grain boundary attack. The attack was associated with a porous, filamentous Cr-rich internal oxide along the alloy grain boundary, with the surrounding region enriched in $\mathrm{Ni}$ metal containing local $\mathrm{Cr}-\mathrm{S}$ nanoparticles. Some occasional Mn-S nanoparticles were also observed. A similar region of local Ni-enrichment and internal oxidation from the 316L mildly-stabilized bio-oil and VGO coprocessing run is shown in Fig. 10. Porous Cr-rich oxide and internal S-rich nanoparticles were again observed, although in this particular location the $\mathrm{S}$ was associated more with $\mathrm{Mn}$ and Mo than Cr. (It should be noted that the Mo L edge and S K edge overlap. The Mo maps were obtained from $\mathrm{K}$ edge data. Therefore, map regions that show only $\mathrm{S}$ do not have Mo, but regions that show Mo could also have S). The porous Cr-rich oxide internal attack intrusion was formed at the interface periphery of the Ni-rich metal region, but was not associated with an alloy grain boundary as was observed for the 304L (Figure 9). This observation is consistent with the intragrain boundary intrusion of internal oxide protrusions observed for the 316L but less frequently for the 304L (Fig. 1d).

Figures 11 and 12 show several local alloy-scale interface regions for the 201 stainless steel from the mildly-stabilized bio-oil and VGO co-processing run, which showed a lesser susceptibility to 
internal attack than the 304L and 316L in the present work (Figures $1-4$ and 6). An inward subscale region (Fig 11) showed mixed, somewhat locally porous $\mathrm{Fe}, \mathrm{Mn}$, and $\mathrm{Cr}$ oxide containing discrete regions of occasional Ni-S rich nanoparticles. Nearby this feature (Figure 12) was a locally continuous Cr-rich oxide region at the alloy-scale interface, below which a Ni-rich region containing Mn-S nanoparticles was observed. Unlike the 304L and 316L (Figures 9-10), the Ni-rich region in advance of the alloy/scale interface generally did not act as a site for inward internal oxidation.

As previously noted in section 3.2, similar microstructural features of Ni-enrichment in the vicinity of internal oxidation and sulfidation attack were reported in an SEM/EPMA analysis of a 316L tube obtained from VTT that was operated under biomass pyrolysis conditions ( 400$500^{\circ} \mathrm{C}$ range) for at least $2000 \mathrm{~h}$ (exact operation time and conditions not available) [44]. To better determine if the features of attack were indeed similar to those observed in the coprocessing environment (Figures 9-10), STEM analysis of a region of internal attack in the 316L pyrolysis tube was pursued in the present work (Figure 13). Similar to the 304L in the mildlystabilized bio-oil and VGO co-processing run (Figure 9), the internal attack in the biomass pyrolysis tube was found to be related to a local Ni-rich region that contained $\mathrm{Cr}-\mathrm{S}$ nanoparticles (Figure 13).

\section{$\underline{3.3 \text { Implications for Corrosion Mechanisms }}$}

In the mildly-stabilized bio-oil co-processing run samples, the internal sulfidation attack revealed by the STEM mapping was associated with $\mathrm{S}$ nanoparticles containing $\mathrm{Cr}$ for the $304 \mathrm{~L}, \mathrm{Cr}, \mathrm{Mn}$, and Mo for the 316L, and Mn and Ni for the 201 stainless steel. In the short-term FCC pilot 
plant co-processing exposure conditions of the present work, as well as short-term exposure under biomass pyrolysis conditions [46], the 201 stainless steel appears more resistant to this form of internal attack than does $316 \mathrm{~L}$ and $304 \mathrm{~L}$ stainless steels. It is hypothesized that the formation of Cr-sulfides may be a key contributor to the internal attack as less $\mathrm{Cr}$ is subsequently available for external, protective oxide scale formation, and is rather locally oxidized at the alloy grain boundaries and/or subscale Ni-metal enriched regions as a porous, inward-growing corrosion product (Figure 9). From this viewpoint, the higher levels of Mn in the 201 stainless steel than in the $304 \mathrm{~L}$ or $316 \mathrm{~L}$ ( $7 \mathrm{wt} . \% \mathrm{Mn}$ in $201 \mathrm{vs.} 1 \mathrm{wt} . \%$ range for $304 \mathrm{~L}$ and $316 \mathrm{~L}$, Table 1 ) are hypothesized to more effectively getter ingressed S (Mn-sulfide is more thermodynamically stable than Cr-sulfide [49]), limiting Cr-S formation and thus mitigating the internal attack by permitting $\mathrm{Cr}$ to more readily participate in external oxide scaling. (It is also possible that the Mn incorporated in the Fe-Cr oxide scale (Fig. 6) may also contribute to better protection in the co-processing environment). What is not yet clear is whether the local Ni-metal enrichment is associated with the initiation of internal attack (with 4 wt.\% Ni in the 201 stainless steel, compared to $8-14$ wt. $\% \mathrm{Ni}$ in $304 \mathrm{~L}, 316 \mathrm{~L}$, and $317 \mathrm{~L}$, Table 1 , being advantageous), or if the local Ni-enrichment is simply a byproduct of the internal attack. If a byproduct of the internal attack, the enrichment of $\mathrm{Ni}$ at the alloy-scale interface/subscale region can result from both extensive $\mathrm{Fe}$ incorporation into the external oxide scale (Fe-oxides are less protective, faster growing than Cr-oxides), as well as the porous, filamentous $\mathrm{Cr}$-rich internal oxide, which results in local $\mathrm{Cr}$ depletion in the adjacent metal, the preferential consumption of $\mathrm{Fe}$ and/or $\mathrm{Cr}$ by oxidation resulting in the effective enrichment of the alloy in $\mathrm{Ni}$ 
Qualitatively, moderately greater scaling and internal attack were observed with use of the mildly-stabilized bio-oil, which had the highest oxygenate content (28 wt.\%) of the 3 levels examined (Table 2). However, the co-processing runs were short-term (57-75 h) and only 3 wt. $\%$ of the mildly-stabilized bio-oil, and up to $10 \mathrm{wt} \%$ of the moderately-stabilized and severelystabilized bio-oils were successfully co-processed. Thus the environment was dominated by the VGO component from a proportion standpoint. From a simplistic viewpoint, the VGO was high in $\mathrm{S}$ content $(0.35 \mathrm{wt} . \%)$ but low in $\mathrm{O}$ (typically $<0.5 \mathrm{wt} . \%)$, whereas the bio-oils were low in $\mathrm{S}$ (< 0.01 wt.\%) but high in oxygenates ( 2 to $28 \mathrm{wt} . \%$ ). A synergistic enhancement in $\mathrm{O}$ and $\mathrm{S}$ related corrosion attack is certainly conceivable and suggested by the current findings in bio-oil + VGO co-processing using the 28 wt. $\%$ O mildly-stabilized bio-oil, but more extensive experimentation would be required to confirm such a mechanism. The seemingly similar internal oxidation and sulfidation attack microstructures observed in co-processing (Figures 9-12) and biomass pyrolysis (Figure 13) environments is also of interest, especially given the high S levels in VGO vs. low $\mathrm{S}$ levels in biomass pyrolysis. Some caution should be exercised given the differences in exposure temperatures, times, and environmental species conditions, but the present findings merit further consideration of these similarities for stainless steels in biomass related process environments.

From an alloy design and selection standpoint, the present findings suggest that type 201 and related low Ni/high Mn stainless steels may offer the potential for greater corrosion resistance in mixed oxidation-sulfidation environments such as those encountered in FCC, as well as biomassrelated process environments, than more commonly used 304L and 316L stainless steels. The use of 201 would be of particular interest as it is less costly than the 300 series stainless steels. It 
would be important to utilize a low carbon or stabilized variation to prevent sensitization/Crcarbide formation degrading corrosion resistance during long-term operation in the $400-700^{\circ} \mathrm{C}$ temperature range of interest. Future work will need to determine whether this local internal attack observed in short term exposures is a transient phenomenon limited to the early stages of corrosion, or if it continues to grow with longer exposure times, at sufficiently rapid rates such that it can impact component lifetime. Also of interest is if the improved corrosion resistance observed for 201 stainless steel in these short term exposures is maintained long-term. Multiple time periods of exposure per alloy type to establish corrosion kinetics and scale/internal attack growth trends, with much longer exposure durations are needed.

\subsection{Conclusions}

A range of stainless steels alloys $(409,410,304 \mathrm{~L}, 316 \mathrm{~L}, 317 \mathrm{~L}$, and 201) was exposed, in-situ, in a pilot-scale used for FCC co-processing of VGO with 3 to 10 weight \% pine-derived pyrolysis bio-oils that had been catalytically hydrotreated to varying degrees of hydrodeoxygenation ( $\sim 2$ to 28 weight $\%$ oxygen). A catalyst temperature of $704^{\circ} \mathrm{C}$, a reaction exit temperature of $520^{\circ} \mathrm{C}$, and total co-processing run times of $57-75 \mathrm{~h}$ were studied.

1) The greatest extent of corrosion for all alloys was qualitatively observed in the co-processing runs using the mildly-stabilized bio-oil with the highest oxygen content ( $28 \%$ oxygen) The coprocessing runs using the moderately ( $\sim 11 \%$ oxygen) and severely stabilized ( $\sim 2 \%$ oxygen) bio-oil, as well as a $100 \%$ VGO control run exhibited lesser, qualitatively comparable extents of corrosion. 
2) The 201 stainless steel generally exhibited the thinnest oxide scales and least extent of internal attack, suggesting greater corrosion resistance in the VGO and co-processing run environments than the more costly, 304L, 316L, and 317L stainless steels.

3) Internal attack of stainless steels exposed in co-processing environments was related to local, porous internal Cr-rich oxide formation, associated with local Ni-metal enrichment and S-rich nanoparticles, primarily containing $\mathrm{Cr}$ or Mn. The lesser extent of attack observed for 201 stainless steel appears to be related in part to more effective gettering of S by higher levels of $\mathrm{Mn}$ additions in the alloy, which limits Cr-S formation and leaves more $\mathrm{Cr}$ available for external, protective oxide scale formation than was observed for 304L, 316L, and 317L stainless steels. Similar internal attack features in 304L and 316L were observed in short-term FCC pilot plant VGO + bio-oil co-processing conditions and longer-term $(2000 \mathrm{~h}+)$ biomass pyrolysis conditions, suggesting future considerations for a common mechanism(s) of attack in these biomass-related processing environments.

\section{Acknowledgements}

The authors thank T.M. Lowe, A. Willoughby, and T. Jordan for assistance with the experimental work at ORNL, and the DCR operators at Grace, M. Bierly, K. Christopher, F. Demory, S. Johnson, S. Joyner, K. Kreipl and J. Thompson, for their diligence and persistence in co-processing the challenging bio-oil feeds. The authors also thank Tesoro for VGO samples, VTT Technical Research Centre of Finland for bio-oil, and T. Bridgwater and D. Nowakowski for consultation on hydrotreating. S. Dryepondt, M Frith, B.A. Pint, and T.J. Theiss provided 
helpful comments for the manuscript. This research was supported by the U.S. Department of Energy (DOE) under the Bioenergy Technologies Office. Oak Ridge National Laboratory is managed by the UT-Battelle, LLC, for DOE under contract DE-AC05-00OR22725.

\section{References}

1. R. Saidur, E.A. Abdelaziz, A. Demirbas, M.S. Hossain, S. Mekhilef, A review on biomass as a fuel for boilers, Renewable \& Sustainable Energy Reviews, 15 (2011) 2262-2289.

2. R.A. Antunes, M.C.L. de Oliveira, Corrosion in biomass combustion: A materials selection analysis and its interaction with corrosion mechanisms and mitigation strategies, Corros. Sci., 76 (2013) 6-26.

3. S.S. Toor, L. Rosendahl, A. Rudolf, Hydrothermal liquefaction of biomass: A review of subcritical water technologies, Energy, 36 (2011) 2328-2342.

4. F. Behrendt, Y. Neubauer, M. Oevermann, B. Wilmes, N. Zobel, Direct liquefaction of biomass, Chemical Engineering \& Technology, 31 (2008) 667-677.

5. A. Demirbas, Competitive liquid biofuels from biomass, Applied Energy, 88 (2011) 17-28.

6. L.H. Zhang, C.B. Xu, P. Champagne, Overview of recent advances in thermo-chemical conversion of biomass, Energy Convers. Manage., 51 (2010) 969-982.

7. G.W. Huber, S. Iborra, A. Corma, Synthesis of transportation fuels from biomass: Chemistry, catalysts, and engineering, Chem. Rev., 106 (2006) 4044-4098.

8. A.V. Bridgwater, G.V.C. Peacocke, Fast pyrolysis processes for biomass, Renewable \& Sustainable Energy Reviews, 4 (2000) 1-73.

9. D.C. Elliott, Historical developments in hydroprocessing bio-oils, Energy \& Fuels, 21 (2007) 1792-1815.

10. S. Czernik, A.V. Bridgwater, Overview of applications of biomass fast pyrolysis oil, Energy \& Fuels, 18 (2004) 590-598.

11. J.R. Keiser, M.P. Brady, R.M. Connatser, S.A. Lewis, Degradation of Structural Alloys in Biomass-Derived Pyrolysis Oil, J-for-Journal of Science \& Technology for Forest Products and Processes, 3 (2013) 16-22.

12. G.W. Huber, A. Corma, Synergies between bio- and oil refineries for the production of fuels from biomass, Angewandte Chemie-International Edition, 46 (2007) 7184-7201. 
13. E. Torsner, Solving corrosion problems in biofuels industry, Corrosion Engineering Science and Technology, 45 (2010) 42-48.

14. A. Corma, C. Martinez, F.V. Melo, L. Sauvanaud, J.Y. Carriat, A new continuous laboratory reactor for the study of catalytic cracking, Applied Catalysis a-General, 232 (2002) 247-263.

15. A. Corma, L. Sauvanaud, FCC testing at bench scale: New units, new processes, new feeds, Catal. Today, 218 (2013) 107-114.

16. K. Bryden, U. Singh, M. Berg, S. Brandt, R. Schiller, W.-C. Cheng. Fluid Catalytic Cracking (FCC): Catalysts and Additives. Kirk-Othmer Encyclopedia of Chemical Technology. (2015) 137.

17. Energy Information Administration, Refinery Outages: Description and Potential Impact on Petroleum Product Prices, U.S. Department of Energy, Mar. 2007. http://www.eia.gov/analysis/requests/2007/SROOG200701.pdf

18. A. Ibarra, E. Rodriguez, U. Sedran, J.M. Arandes, J. Bilbao, Synergy in the Cracking of a Blend of Bio-oil and Vacuum Gasoil under Fluid Catalytic Cracking Conditions, Industrial \& Engineering Chemistry Research, 55 (2016) 1872-1880.

19. M. Berchtold, J. Fimberger, A. Reichhold, P. Pucher, Upgrading of heat carrier oil derived from liquid-phase pyrolysis via fluid catalytic cracking, Fuel Process. Technol., 142 (2016) 92 99.

20. G. Fogassy, N. Thegarid, G. Toussaint, A.C. van Veen, Y. Schuurman, C. Mirodatos, Biomass derived feedstock co-processing with vacuum gas oil for second-generation fuel production in FCC units, Applied Catalysis B-Environmental, 96 (2010) 476-485.

21. A.D. Pinho, M.B.B. de Almeida, F.L. Mendes, V.L. Ximenes, L.C. Casavechia, Coprocessing raw bio-oil and gasoil in an FCC Unit, Fuel Process. Technol., 131 (2015) 159-166.

22. C.X. Wang, M.R. Li, Y.M. Fang, Coprocessing of Catalytic-Pyrolysis-Derived Bio-Oil with VGO in a Pilot-Scale FCC Riser, Industrial \& Engineering Chemistry Research, 55 (2016) 35253534.

23. C. Lindfors, V. Paasikallio, E. Kuoppala, M. Reinikainen, A. Oasmaa, Y. Solantausta, Coprocessing of Dry Bio-oil, Catalytic Pyrolysis Oil, and Hydrotreated Bio-oil in a Micro Activity Test Unit, Energy \& Fuels, 29 (2015) 3707-3714.

24. A.A. Lappas, S. Bezergianni, I.A. Vasalos, Production of biofuels via co-processing in conventional refining processes, Catal. Today, 145 (2009) 55-62.

25. M.S. Talmadge, R.M. Baldwin, M.J. Biddy, R.L. McCormick, G.T. Beckham, G.A. Ferguson, S. Czernik, K.A. Magrini-Bair, T.D. Foust, P.D. Metelski, C. Hetrick, M.R. Nimlos, A 
perspective on oxygenated species in the refinery integration of pyrolysis oil, Green Chemistry, 16 (2014) 407-453.

26. J.A. Melero, G. Calleja, A. Garcia, M. Clavero, E.A. Hernandez, R. Miravalles, T. Galindo, Storage stability and corrosion studies of renewable raw materials and petrol mixtures: A key issue for their co-processing in refinery units, Fuel, 89 (2010) 554-562.

27. A.H. Zacher, M.V. Olarte, D.M. Santosa, D.C. Elliott, S.B. Jones, A review and perspective of recent bio-oil hydrotreating research, Green Chemistry, 16 (2014) 491-515.

28. K. Bryden, G. Weatherbee, and E. T. Habib, Jr., Flexible Pilot Plant Technology for Evaluation of Unconventional Feedstocks and Processes, American Fuel \& Petrochemical Manufacturers (AFPM)Annual Meeting, Paper AM-13-04, San Antonio, Texas, Mar. 2013.

29. Role of Stainless Steel in Petroleum Refining (9021), Nickel Institute, Toronto, Canada https://www.nickelinstitute.org/en/TechnicalLiterature/AISI/9021_RoleofStainlessSteelinPetrole umRefining.aspx

30. D. C. Agarwal and D.J. Chronister, RMC-05-81 Metallurgy 201: Application and Limitations of Existing and Newer Alloys in Hydrocarbon Industry, American Fuel and Petrochemical Manufacturers, Washington, DC USA (2005).

31. R. Heidersbach, Metallurgy and Corrosion Control in Oil and Gas Production, John Wiley and Sons, Hoboken, New Jersey, USA (2011).

32. R.C. John, A.D. Pelton, A.L. Young, W.T. Thompson, I.G. Wright, and T.M. Bessman, Assessing Corrosion in Oil Refining and Petrochemical Processing, Materials Research, 7(1) (2004) 163-173.

33. R.C. John, Exploitation of Data of Alloy Corrosion in High-Temperature Gases, Materials Science Forum, 369-372 (2001) 881-922.

34. C. S. Giggins and F. S. Pettit, Corrosion of Metals and Alloys in Mixed Gas Environments at Elevated Temperatures, Oxidation of Metals, 14 (5) (1980) 363-413.

35. D. J. Young and S. Watson, High-Temperature Corrosion in Mixed Gas Environments, Oxidation of Metals, 44 (1/2) (1995), 239-264.

36. D.J. Young, High Temperature Oxidation and Corrosion of Metals, 2nd Edition, Elsevier Science, Amsterdam, Netherlands (2016).

37. J. Charles, B. Bonnefois Et F. Dupoiron, Sulfuration et Carburation d'un Acier Inoxydable AISI 304H par Gaz Chauds dans un Regengrateur de Catalyseurs d'Unitgs de Cracking, Materials Science and Engineering, 87 (1987) 151-159 151 
38. F. Rizzo, M. Monteiro, M. F. Lopes, I. Caminha, C. Zeng, and M. Piza Paes, Evaluation of the Corrosion Resistance of Thermal-Spray Coatings under Oxidant Atmosphere in a Fluid Catalytic-Cracking Unit, Oxidation of Metals, 57 (3/4) (2002) 323-338.

39. A. Zacher, Optimizing Co-Processing of Bio-Oil in Refinery Unit Operations Using a Davison Circulating Riser (DCR), DOE Bioenergy Technologies Office (BETO) 2015 Project Peer Review, http://www.energy.gov/sites/prod/files/2015/04/f21/thermochemical_conversion_zacher_242402 .pdf

40. G.W. Young, G.D. Weatherbee, "FCCU Studies with an Adiabatic Circulating Pilot Unit," AIChE Annual Meeting, November, 1989.

41. A. Oasmaa, Y. Solantausta, Yrjö, V. Arpiainen, E. Kuoppala, K. Sipilä,. Fast Pyrolysis BioOils from Wood and Agricultural Residues. Energy \& Fuels, 24 (2010), 1380-1388.

42 D.C. Elliott, T.R. Hart, G.G. Neuenschwander, L.J. Rotness, M.V. Olarte, A.H. Zacher, Y. Solantausta, Catalytic Hydroprocessing of Fast Pyrolysis Bio-oil from Pine Sawdust, Energy \& Fuels, 26 (2012) 3891-3896

43. J. R. Keiser, M. P. Brady, S. A. Lewis Sr, R. M. Connatser, M. D Kass, D. N. Leonard, Corrosion Issues In Biomass-Derived Oils, Electric Power Research Institute, EPRI International Conference on Corrosion in Power Plants, Oct 13-15, 2015 San Diego, California, USA

44. J. R. Keiser, M. P. Brady, S. A. Lewis Sr, R. M. Connatser, M. D Kass, D. N. Leonard, C. J. Janke, Materials Issues In Thermochemical Production, Processing and Utilization of Bio-Oil, STG38, NACE Corrosion 2016 Conference and Expo, Vancouver, Canada,

45. J. R. Keiser, M. P. Brady, S. A. Lewis Sr, R. M. Connatser, M. D Kass, D. N. Leonard, Materials Compatibility Issues With Biomass-Derived Oils, 2015 TAPPI PEERS Conference, Atlanta, GA Oct 25-28, 2015

46 M.P. Brady, J.R. Keiser, D.N. Leonard, L. Whitmer, J.K. Thomson, Corrosion Considerations for Thermochemical Biomass Liquefaction Process Systems in Biofuel Production, JOM, 66 (2014) 2583-2592.

47. G. Bamba, Y. Wouters, A. Galerie, F. Charlot, and A. Dellali, Thermal oxidation kinetics and oxide scale adhesion of $\mathrm{Fe}-15 \mathrm{Cr}$ alloys as a function of their silicon content. Acta Mater. 54 (2006) 3917-3922.

48. M.P. Brady, K. Banta, J. Mizia, N. Lorenz, D.N. Leonard, Y. Yamamoto, M. DeFoort, J.R. Keiser, Alloy Corrosion Considerations in Low-Cost, Clean Biomass Cookstoves for the Developing World, Energy For Sustainable Development (in press). 
49. D.R. Sigler, Aluminum Oxide Adherence on Fe-Cr-A1 Alloys Modified with Group IIIB, IVB, VB, and VIB Elements, Oxidation of Metals, 32, Nos. 5/6 (1989) 337-355.

50. S.C. Okoro, M. Montgomery, F.J. Frandsen, K. Pantleon, High Temperature Corrosion under Laboratory Conditions Simulating Biomass-Firing: A Comprehensive Characterization of Corrosion Products, Energy \& Fuels, 28 (2014) 6447-6458.

51. S.C. Okoro, M. Montgomery, F.J. Frandsen, K. Pantleon, Effect of Water Vapor on High-

Temperature Corrosion under Conditions Mimicking Biomass Firing, Energy \& Fuels, 29 (2015) 5802-5815.

\section{Figure Captions}

Figure Supplemental 1 - a) FCC pilot plant schematic showing insertion location of corrosion test samples inserted at the base of the riser reactor (marked by red arrow). b) alloy test samples attached to weld wire rods for insertion into the FCC pilot plant riser reactor.

Figure 1 - Cross-section backscatter mode SEM images of test alloys exposed in the FCC pilot plant during the mildly-stabilized bio-oil and vacuum gas oil co-processing run. The arrows mark areas of internal attack. a) 410 (Fe-12Cr wt.\% base), b) 201 (Fe-16Cr-4Ni-7Mn wt.\% base), c) 304L (Fe-18Cr-8Ni wt.\% base), and d) 316L (Fe-17Cr-10Ni-2Mo wt.\% base). All alloy images at same magnification.

Figure 2 - Cross-section backscatter mode SEM images of test alloys exposed in the FCC pilot plant during the moderately-stabilized bio-oil and vacuum gas oil co-processing run. a) 201 (Fe16Cr-4Ni-7Mn wt.\% base), b) 304L (Fe-18Cr-8Ni wt.\% base), c) 316L (Fe-17Cr-10Ni-2Mo wt.\% base), and d) 317L (Fe-18Cr-14Ni-3Mo wt.\% base). All alloy images at same magnification. 
Figure 3 - Cross-section backscatter mode SEM images of test alloys exposed in the FCC pilot plant during the severely-stabilized bio-oil and vacuum gas oil co-processing run. a) 410 (Fe12Cr wt.\% base), b) 201 (Fe-16Cr-4Ni-7Mn wt.\% base), c) 304L (Fe-18Cr-8Ni wt.\% base), and d) 316L (Fe-17Cr-10Ni-2Mo wt.\% base). All alloy images at same magnification.

Figure 4 - Cross-section backscatter mode SEM images of test alloys exposed in the FCC pilot plant during the control 100\% vacuum gas oil run. a) 409 (Fe-11Cr wt.\% base), b) 201 (Fe-16Cr4Ni-7Mn wt.\% base), c) 304L (Fe-18Cr-8Ni wt.\% base), and d) 316L (Fe-17Cr-10Ni-2Mo wt.\% base). All alloy images at same magnification.

Figure 5 - Cross-section backscatter mode SEM image and corresponding EPMA elemental maps of 410 stainless steel exposed in the FCC pilot plant during the mildly-stabilized bio-oil and vacuum gas oil co-processing run. Each individual element map is raw counts and plotted as an intensity scale. Black is no signal and higher intensities signify higher counts and therefore higher amounts of the element is present in that pixel.

Figure 6 - Cross-section backscatter mode SEM image and corresponding EPMA elemental maps of 201 stainless steel exposed in the FCC pilot plant during the mildly-stabilized bio-oil and vacuum gas oil co-processing run. Each individual element map is raw counts and plotted as an intensity scale. Black is no signal and higher intensities signify higher counts and therefore higher amounts of the element is present in that pixel.

Figure 7 - Cross-section backscatter mode SEM image and corresponding EPMA elemental maps of 304L stainless steel exposed in the FCC pilot plant during the mildly-stabilized bio-oil 
and vacuum gas oil co-processing run [after reference 45]. Each individual element map is raw counts and plotted as an intensity scale. Black is no signal and higher intensities signify higher counts and therefore higher amounts of the element is present in that pixel.

Figure 8 - Cross-section backscatter mode SEM image and corresponding EPMA elemental maps of 316L stainless steel exposed in the FCC pilot plant during the mildly-stabilized bio-oil and vacuum gas oil co-processing run. Each individual element map is raw counts and plotted as an intensity scale. Black is no signal and higher intensities signify higher counts and therefore higher amounts of the element is present in that pixel.

Figure 9 - Cross-section STEM analysis (a) of internal attack region in 304L stainless steel exposed in the FCC pilot plant during the mildly-stabilized bio-oil and vacuum gas oil coprocessing run (see Fig 7). Each individual element map (b,c) is raw counts and plotted as an intensity scale. Black is no signal and higher intensities signify higher counts and therefore higher amounts of the element is present in that pixel.

Figure 10 - Cross-section STEM analysis of internal attack region in 316L stainless steel exposed in the FCC pilot plant during the mildly-stabilized bio-oil and vacuum gas oil coprocessing run (see Fig 8). Each individual element map is raw counts and plotted as an intensity scale. Black is no signal and higher intensities signify higher counts and therefore higher amounts of the element is present in that pixel.

Figure 11 - Cross-section STEM analysis of internal attack region in 201 stainless steel exposed in the FCC pilot plant during the mildly-stabilized bio-oil and vacuum gas oil co-processing run 
(see Fig 6). Each individual element map is raw counts and plotted as an intensity scale. Black is no signal and higher intensities signify higher counts and therefore higher amounts of the element is present in that pixel.

Figure 12 - Cross-section STEM analysis of region near internal attack in 201 stainless steel exposed in the FCC pilot plant during the mildly-stabilized bio-oil and vacuum gas oil coprocessing run (see Fig. 11). Each individual element map is raw counts and plotted as an intensity scale. Black is no signal and higher intensities signify higher counts and therefore higher amounts of the element is present in that pixel.

Figure 13 - Cross-section analysis of a 316L pyrolyzer tube after $>2000 \mathrm{~h}$ operation in a biomass pyrolysis system. Cross-section SEM and microprobe images after reference 44. STEM analysis of internal grain boundary attack region shows local Ni-enriched region containing $\mathrm{Cr}-\mathrm{S}$ nanoparticles at tip of the reaction front. Each individual element map is raw counts and plotted as an intensity scale. Black is no signal and higher intensities signify higher counts and therefore higher amounts of the element is present in that pixel. 


\section{a) 410 (Fe-12Cr)}

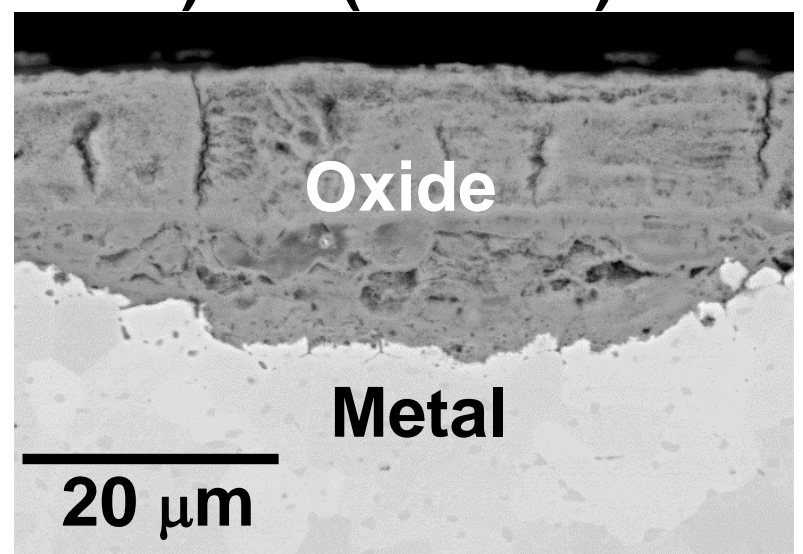

\section{c) $304 \mathrm{~L}(\mathrm{Fe}-18 \mathrm{Cr}-8 \mathrm{Ni})$}

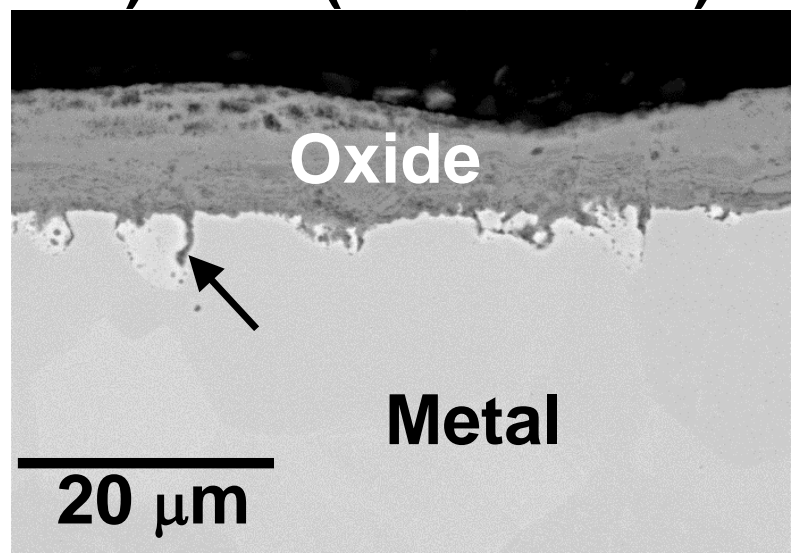

\section{b) 201 (Fe-16Cr-4Ni-7Mn)}

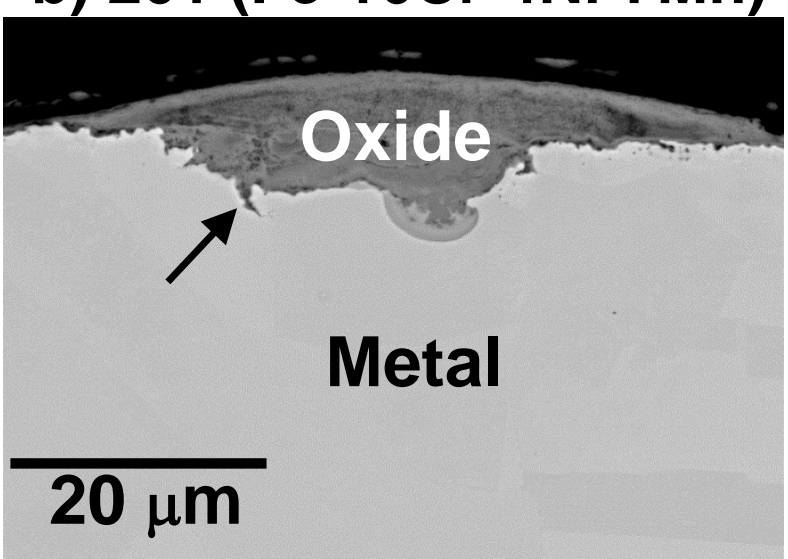

\section{d) 316L (Fe-17Cr-10Ni-2Mo)}

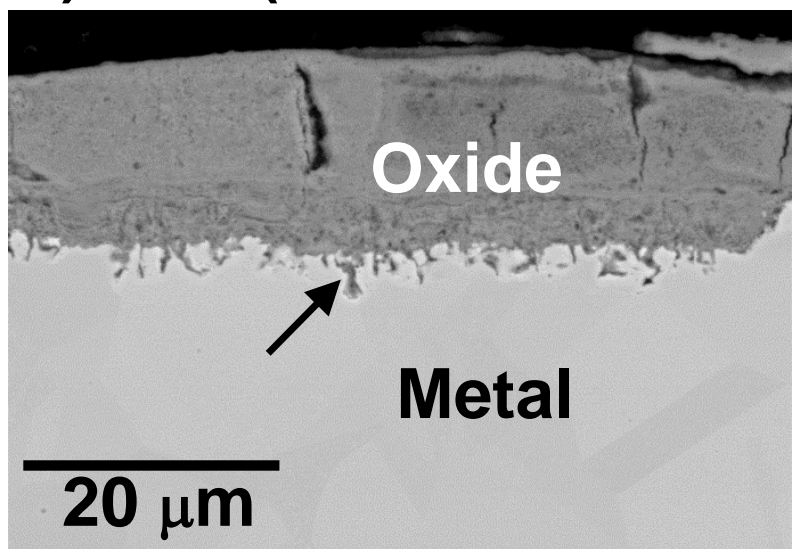

Figure 1 - Cross-section backscatter mode SEM images of test alloys exposed in the FCC pilot plant during the mildly-stabilized bio-oil and vacuum gas oil co-processing run. The arrows mark areas of internal attack. a) 410 (Fe-12Cr wt.\% base), b) 201 (Fe-16Cr-4Ni-7Mn wt.\% base), c) 304L (Fe-18Cr-8Ni wt.\% base), and d) 316L (Fe-17Cr-10Ni-2Mo wt.\% base). All alloy images at same magnification. 


\section{a) 201 (Fe-16Cr-4Ni-7Mn)}

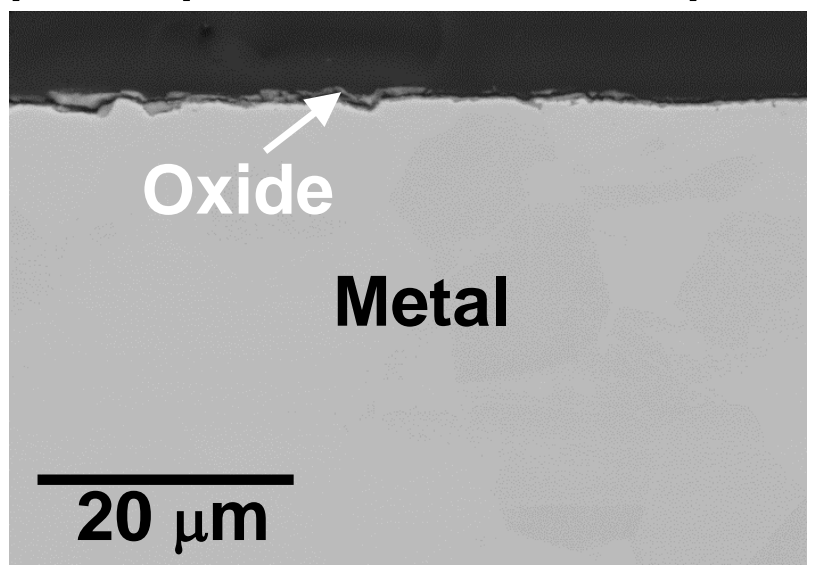

\section{c) $316 \mathrm{~L}(\mathrm{Fe}-17 \mathrm{Cr}-10 \mathrm{Ni}-2 \mathrm{Mo})$}

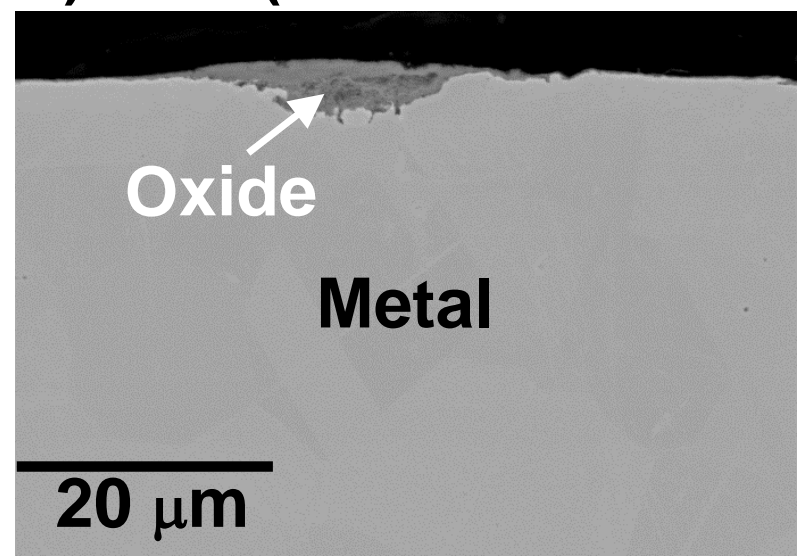

b) 304L (Fe-18Cr-8Ni)

Oxide

Metal

$20 \mu \mathrm{m}$
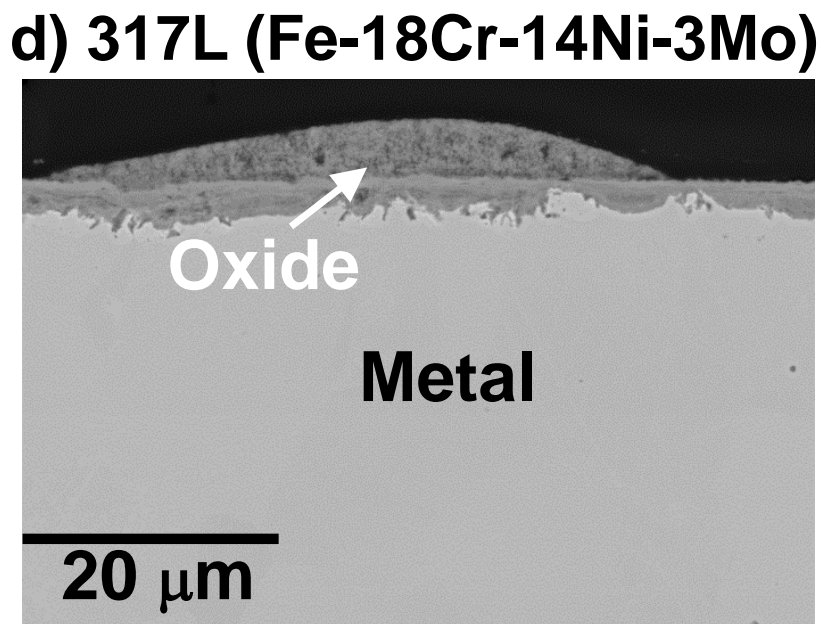

Figure 2 - Cross-section backscatter mode SEM images of test alloys exposed in the FCC pilot plant during the moderately-stabilized bio-oil and vacuum gas oil co-processing run. a) 201 (Fe-16Cr-4Ni7Mn wt.\% base), b) 304L (Fe-18Cr-8Ni wt.\% base), c) 316L (Fe-17Cr-10Ni-2Mo wt.\% base), and d) 317L (Fe-18Cr-14Ni-3Mo wt.\% base). All alloy images at same magnification. 
a) 410 (Fe-12Cr)

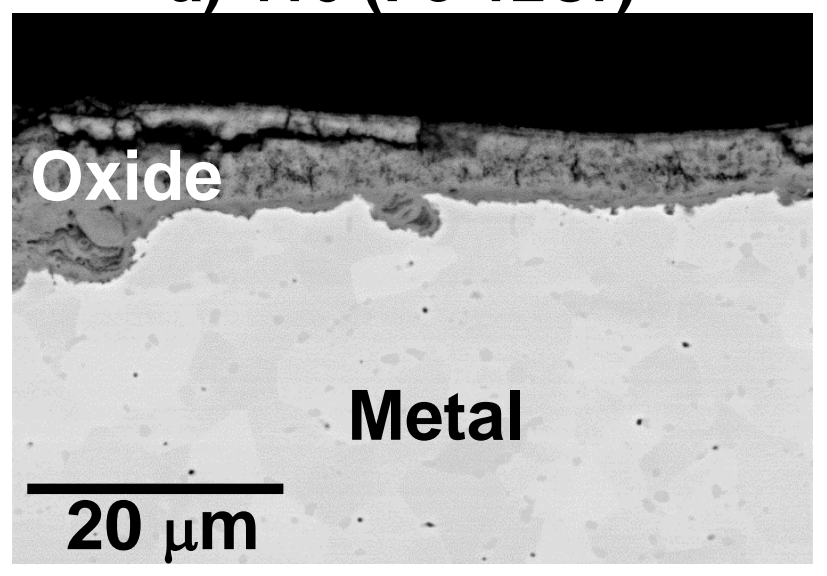

c) $304 \mathrm{~L}(\mathrm{Fe}-18 \mathrm{Cr}-8 \mathrm{Ni})$

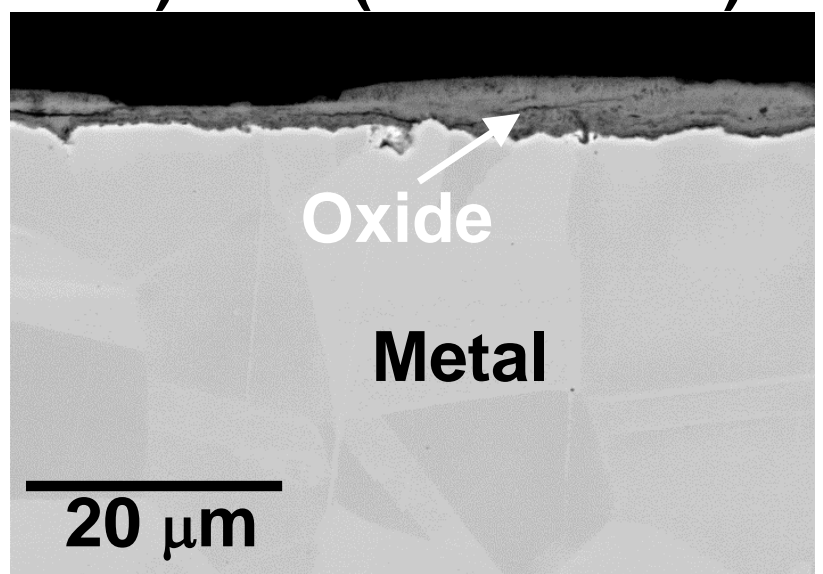

b) 201 (Fe-16Cr-4Ni-7Mn)

\section{Oxide}

\section{Metal}

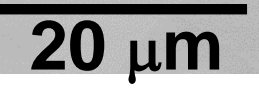

\section{d) $316 \mathrm{~L}(\mathrm{Fe}-17 \mathrm{Cr}-10 \mathrm{Ni}-2 \mathrm{Mo})$}

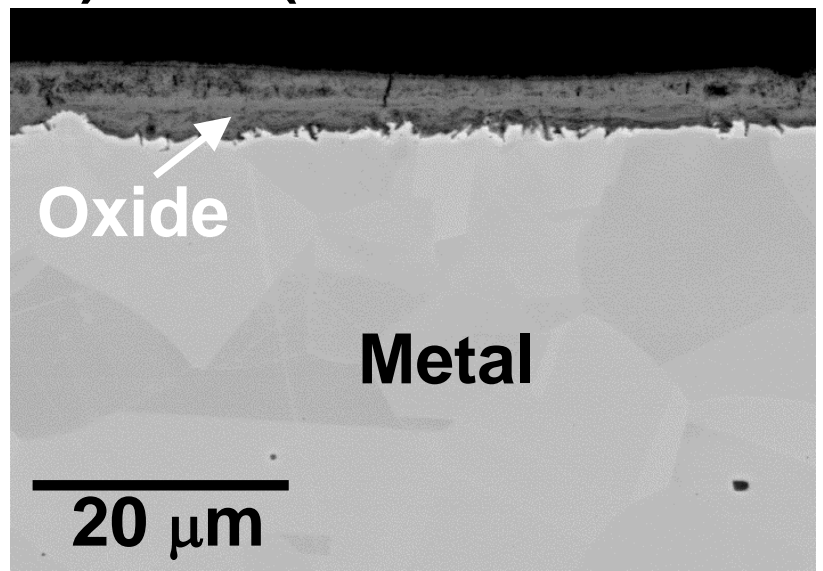

Figure 3 - Cross-section backscatter mode SEM images of test alloys exposed in the FCC pilot plant during the severely-stabilized bio-oil and vacuum gas oil co-processing run. a) 410 (Fe-12Cr wt.\% base), b) 201 (Fe-16Cr-4Ni-7Mn wt.\% base), c) 304L (Fe-18Cr-8Ni wt.\% base), and d) 316L (Fe-17Cr-10Ni2Mo wt.\% base). All alloy images at same magnification. 


\section{a) 409 (Fe-11Cr)}

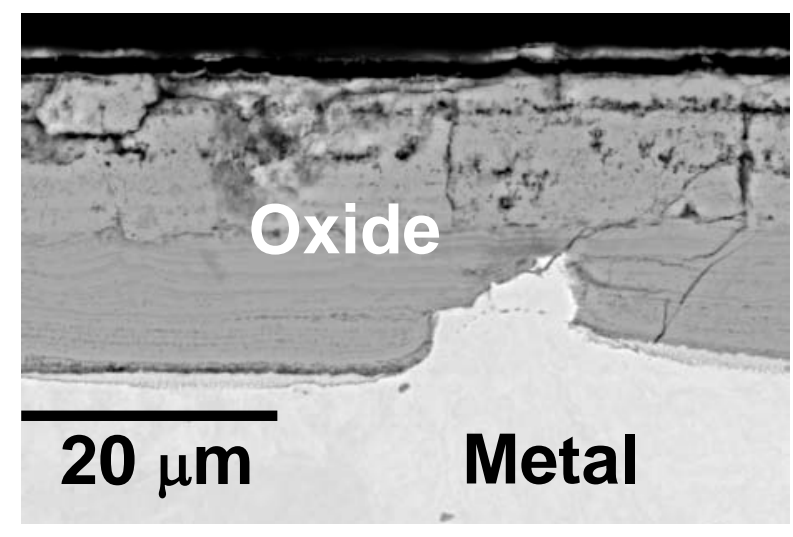

\section{c) $304 \mathrm{~L}(\mathrm{Fe}-18 \mathrm{Cr}-8 \mathrm{Ni})$}

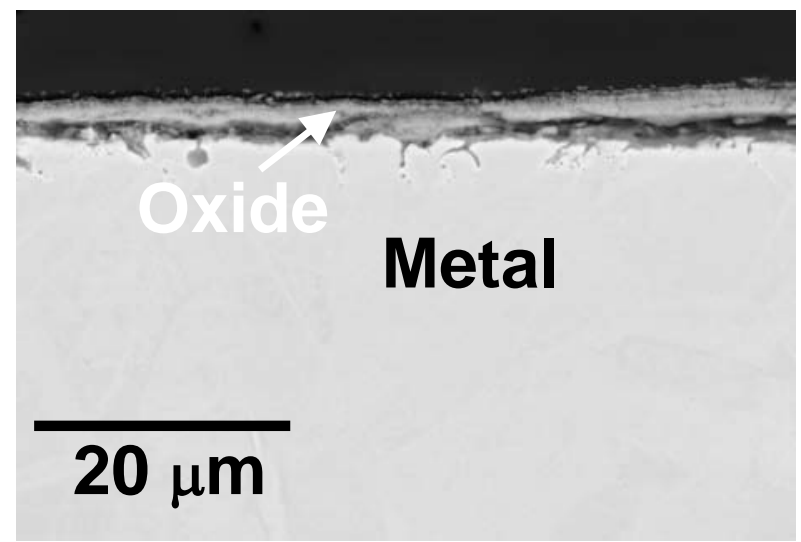

\section{b) 201 (Fe-16Cr-4Ni-7Mn)}

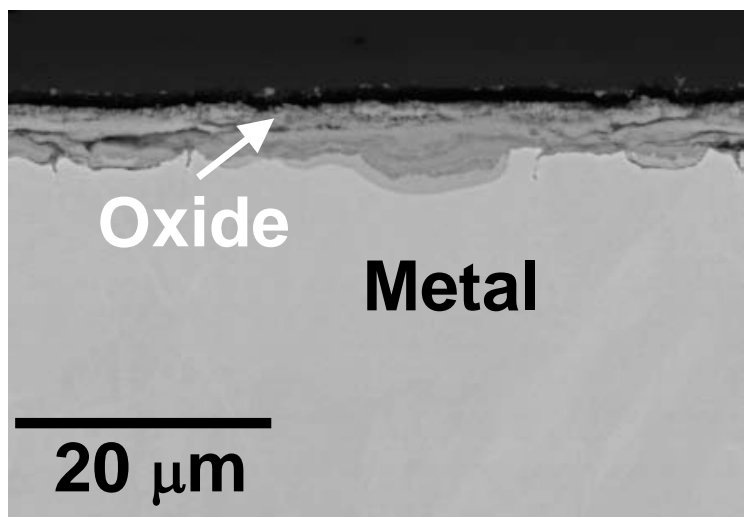

d) 316 L (Fe-17Cr-10Ni-2Mo)

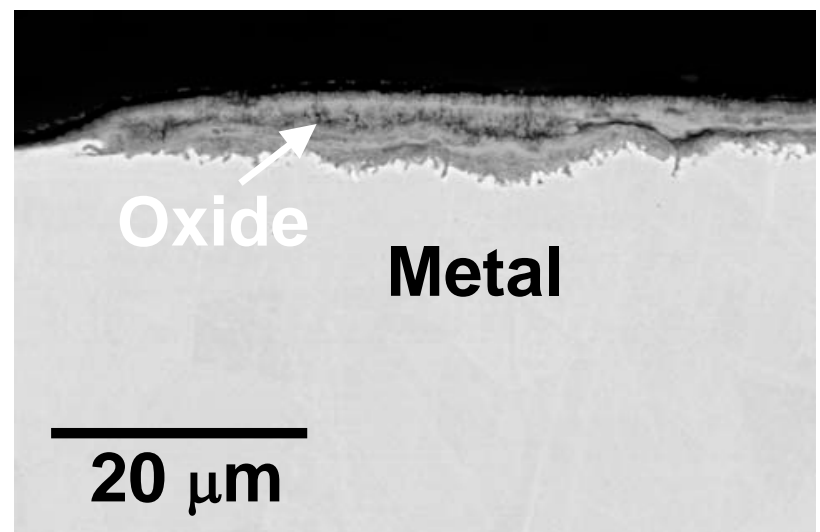

Figure 4 - Cross-section backscatter mode SEM images of test alloys exposed in the FCC pilot plant during the control 100\% vacuum gas oil run. a) 409 (Fe-11Cr wt.\% base), b) 201 (Fe-16Cr-4Ni-7Mn wt.\% base), c) 304L (Fe-18Cr-8Ni wt.\% base), and d) 316L (Fe-17Cr-10Ni-2Mo wt.\% base). All alloy images at same magnification. 

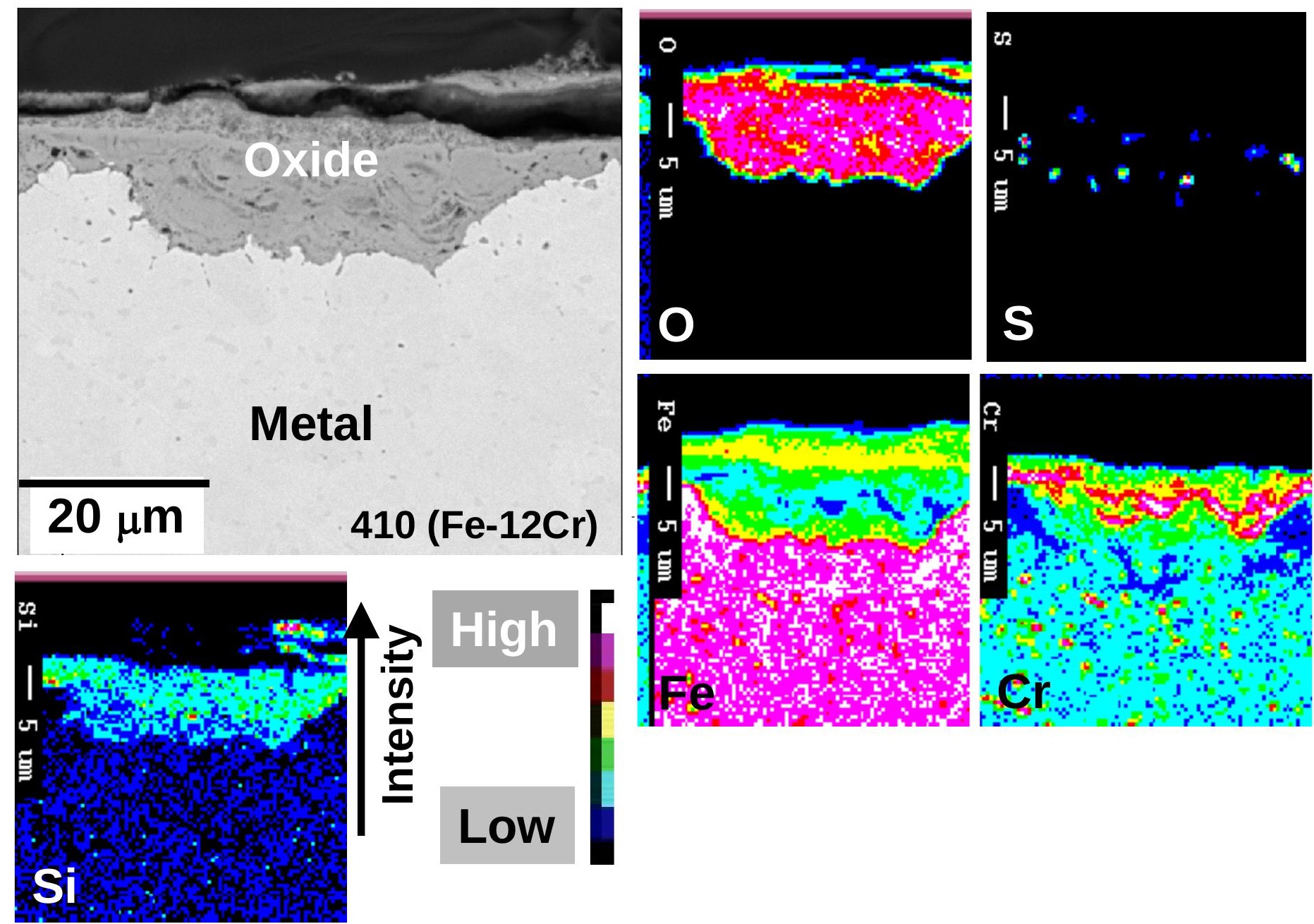

Figure 5 - Cross-section backscatter mode SEM image and corresponding EPMA elemental maps of 410 stainless steel exposed in the FCC pilot plant during the mildly-stabilized bio-oil and vacuum gas oil co-processing run. Each individual element map is raw counts and plotted as an intensity scale. Black is no signal and higher intensities signify higher counts and therefore higher amounts of the element is present in that pixel. 


\section{L ( $\mathrm{Fe}-18 \mathrm{Cr}-8 \mathrm{Ni})$}

\section{Oxide}

\section{Metal}
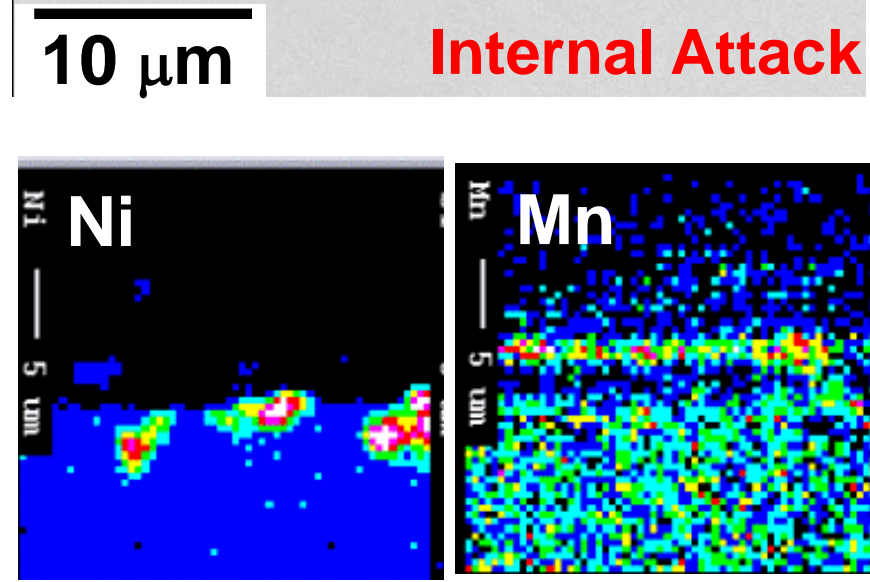
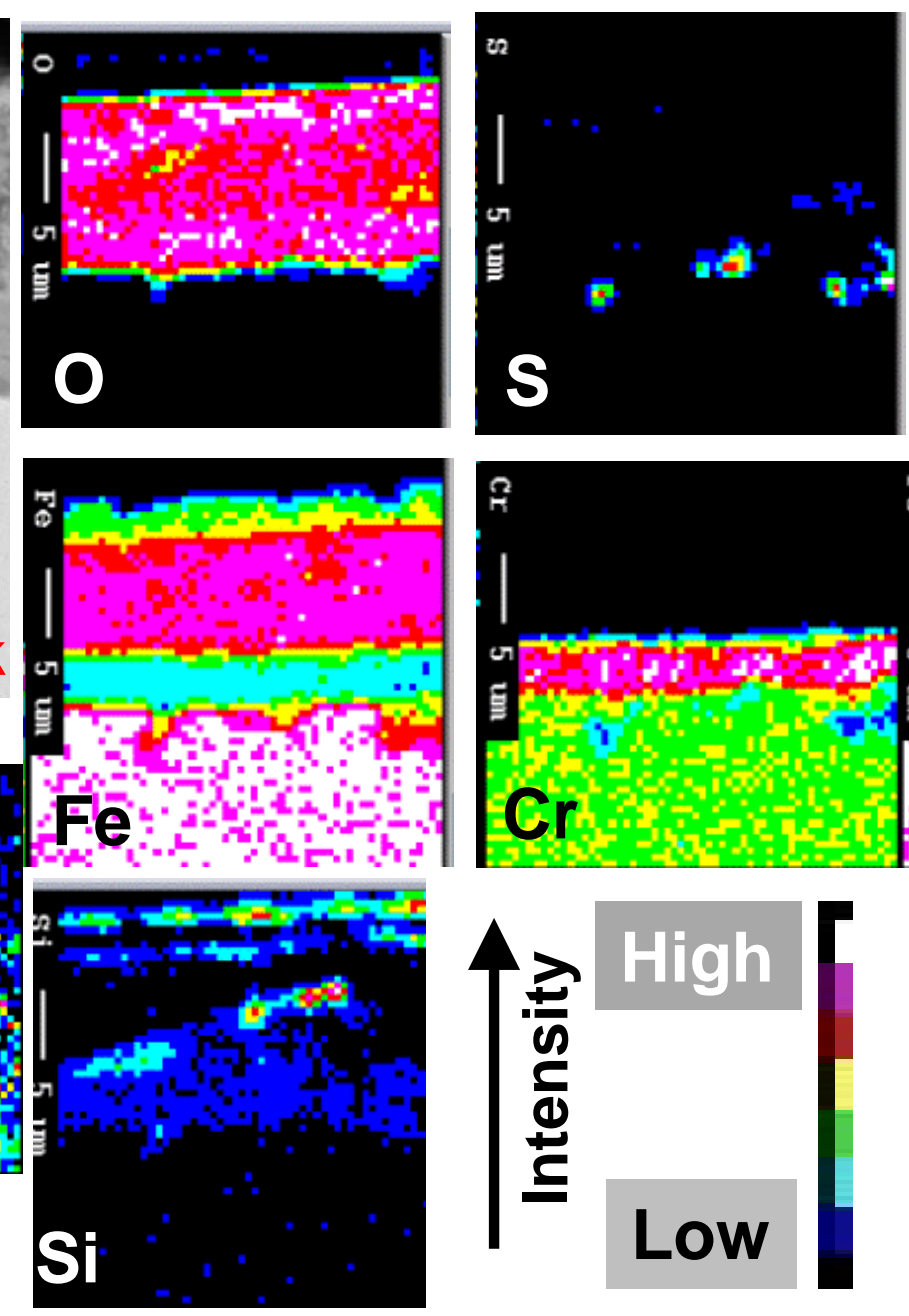
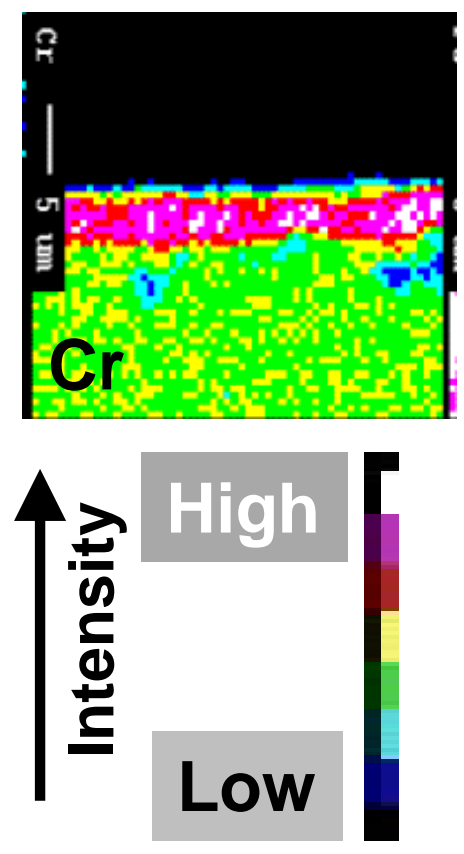

Figure 7 - Cross-section backscatter mode SEM image and corresponding EPMA elemental maps of 304L stainless steel exposed in the FCC pilot plant during the mildly-stabilized bio-oil and vacuum gas oil co-processing run [after reference 45]. Each individual element map is raw counts and plotted as an intensity scale. Black is no signal and higher intensities signify higher counts and therefore higher amounts of the element is present in that pixel. 

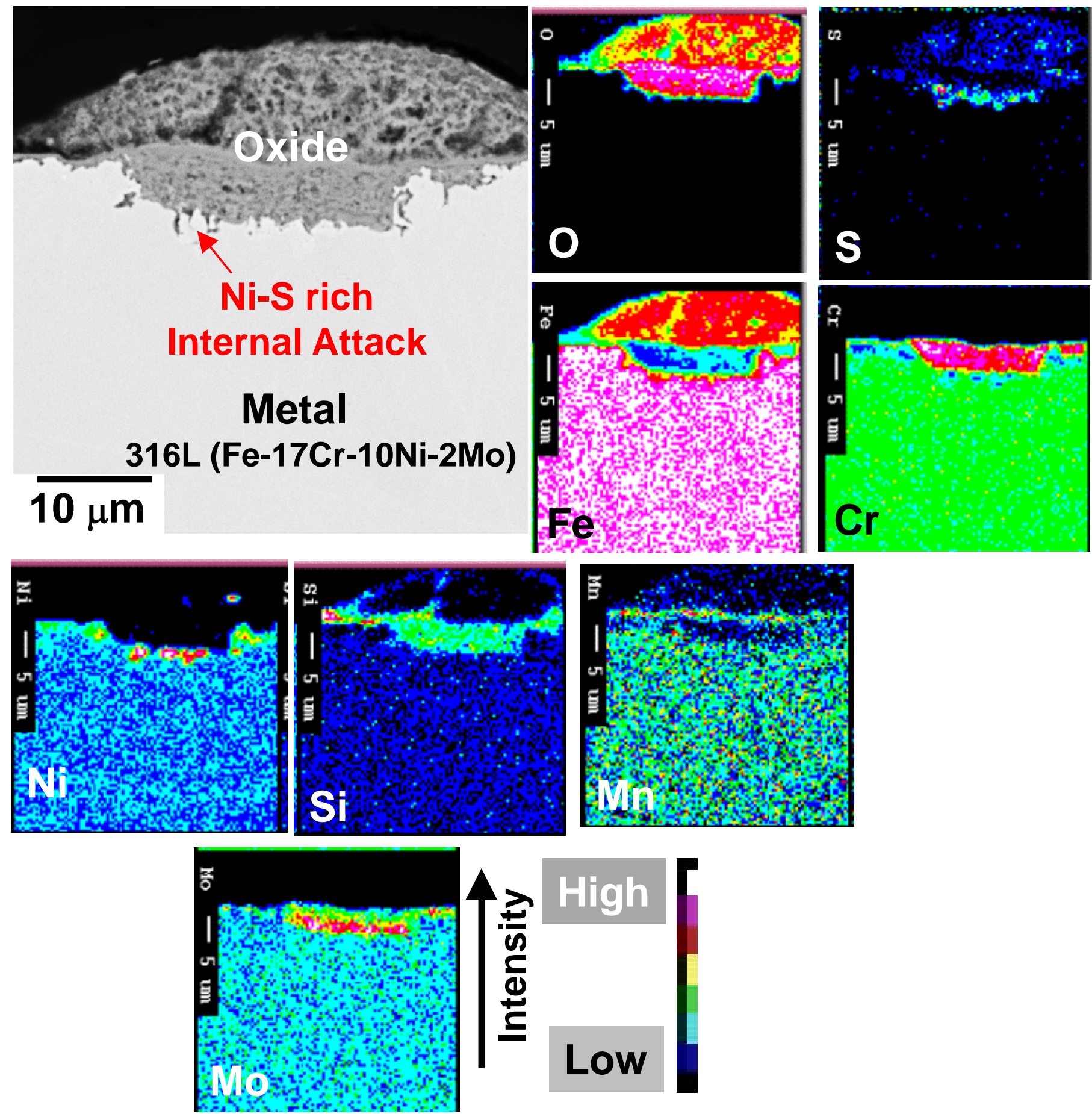

Figure 8 - Cross-section backscatter mode SEM image and corresponding EPMA elemental maps of 316L stainless steel exposed in the FCC pilot plant during the mildly-stabilized bio-oil and vacuum gas oil co-processing run. Each individual element map is raw counts and plotted as an intensity scale. Black is no signal and higher intensities signify higher counts and therefore higher amounts of the element is present in that pixel. 


\section{a) Cross-Section STEM Image}

b) Mapped STEM Image

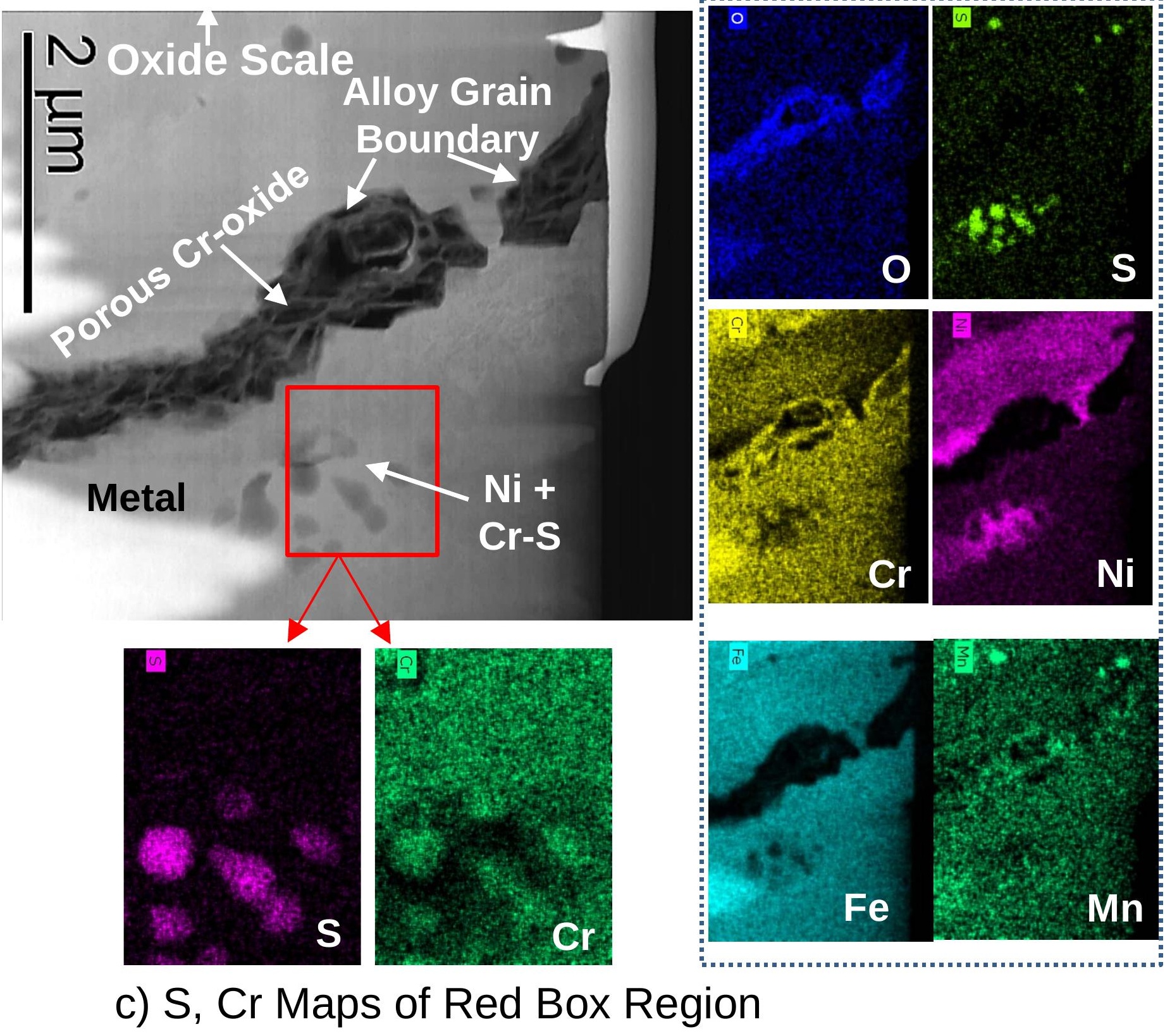

Figure 9 - Cross-section STEM analysis (a) of internal attack region in 304L stainless steel exposed in the FCC pilot plant during the mildly-stabilized bio-oil and vacuum gas oil co-processing run (see Fig 7). Each individual element map (b,c) is raw counts and plotted as an intensity scale. Black is no signal and higher intensities signify higher counts and therefore higher amounts of the element is present in that pixel. 

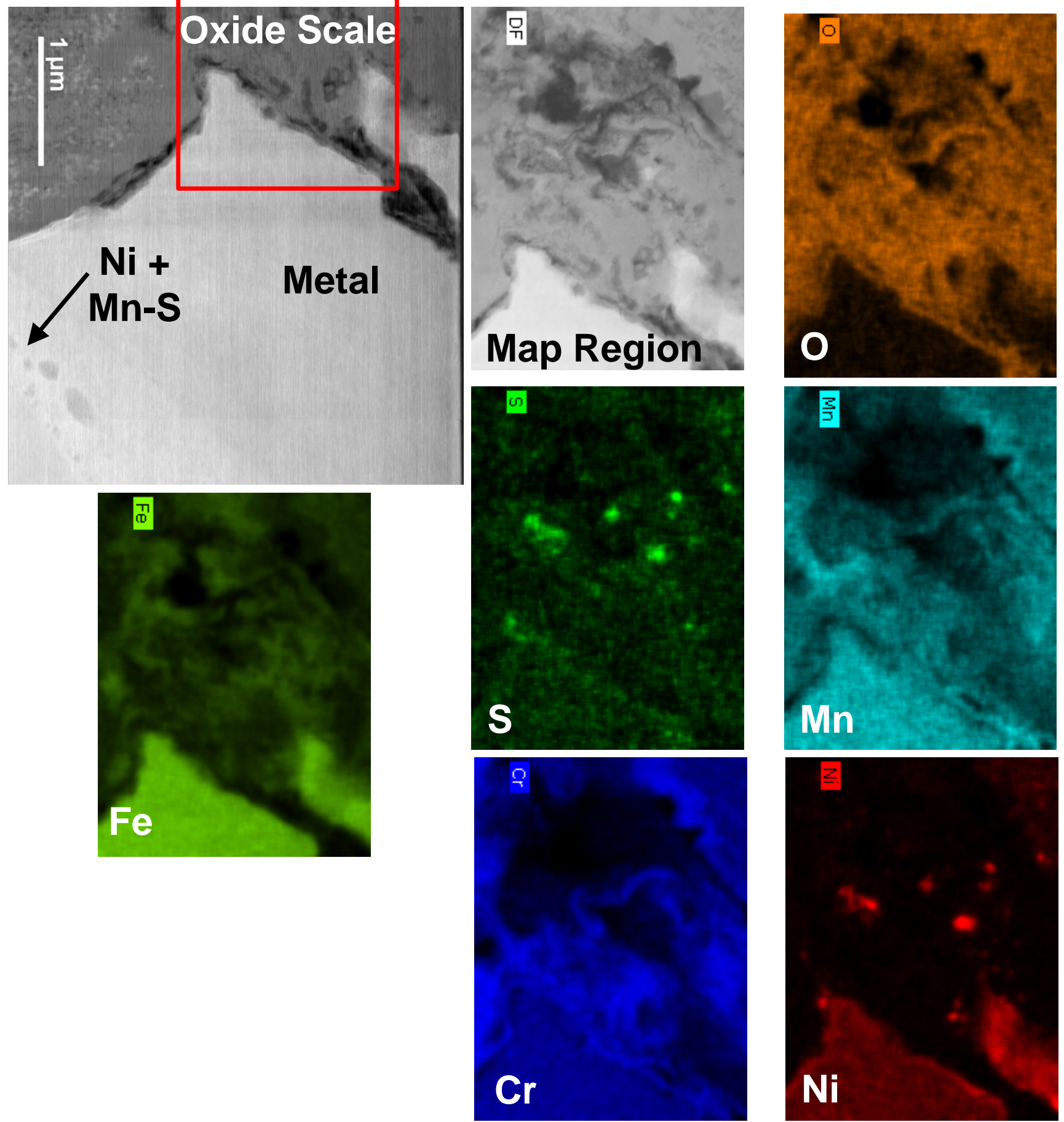

Figure 11 - Cross-section STEM analysis of internal attack region in 201 stainless steel exposed in the FCC pilot plant during the mildly-stabilized bio-oil and vacuum gas oil co-processing run (see Fig 6). Each individual element map is raw counts and plotted as an intensity scale. Black is no signal and higher intensities signify higher counts and therefore higher amounts of the element is present in that pixel. 

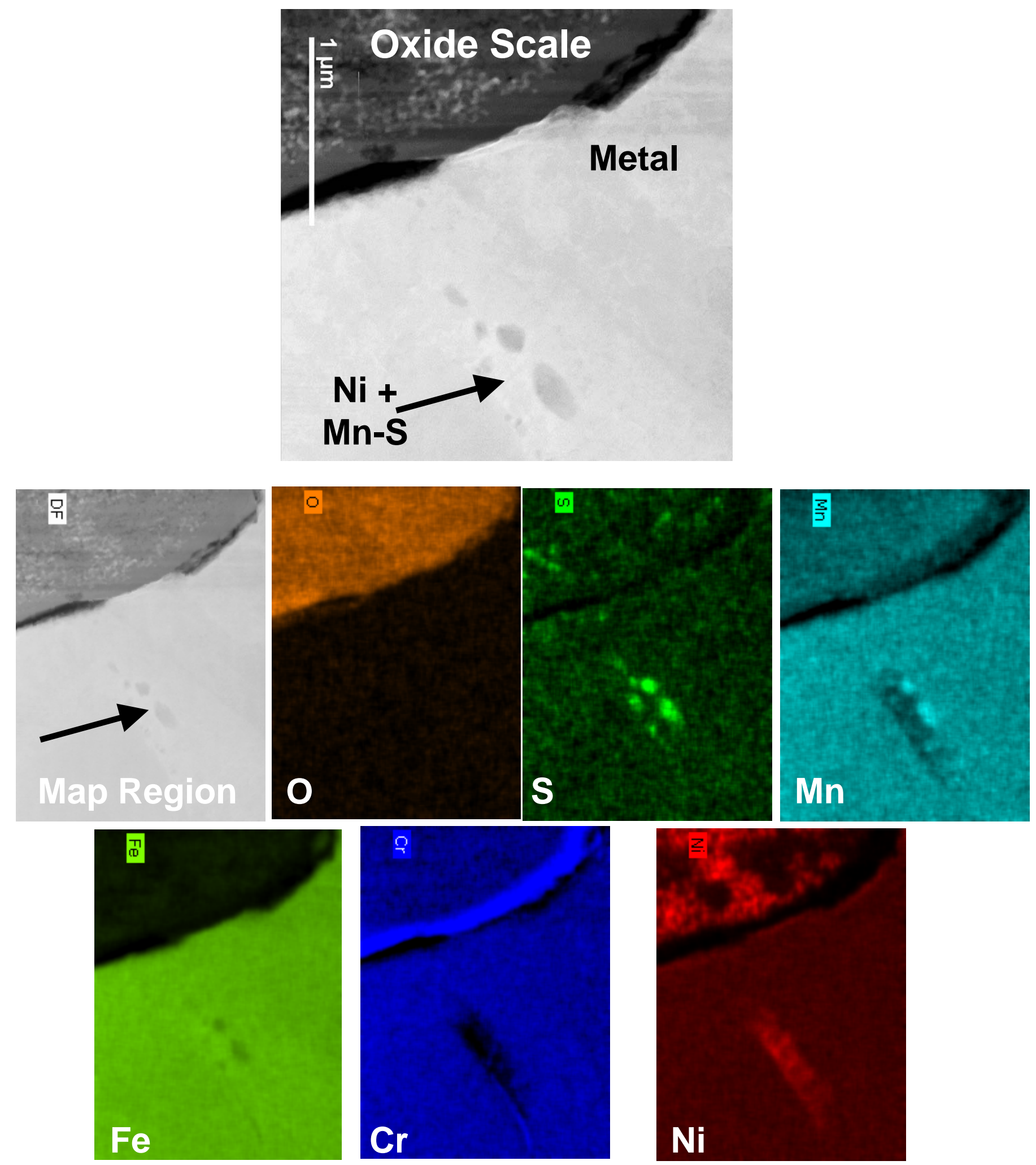

Figure 12 - Cross-section STEM analysis of region near internal attack in 201 stainless steel exposed in the FCC pilot plant during the mildly-stabilized bio-oil and vacuum gas oil co-processing run (see Fig. 11). Each individual element map is raw counts and plotted as an intensity scale. Black is no signal and higher intensities signify higher counts and therefore higher amounts of the element is present in that pixel. 


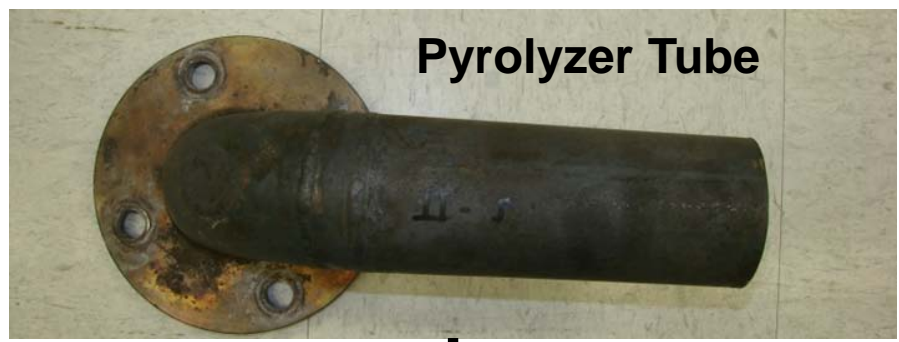

\section{Cross-Section SEM}

\section{Grain Boundary Internal Attack}

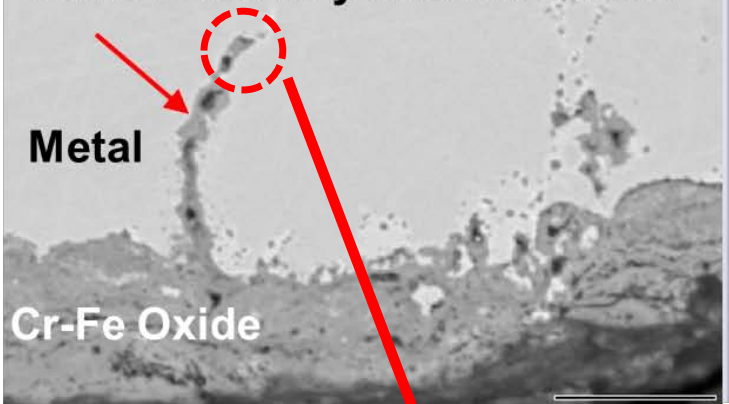

Tube Inner Surface

\section{Microprobe Maps}
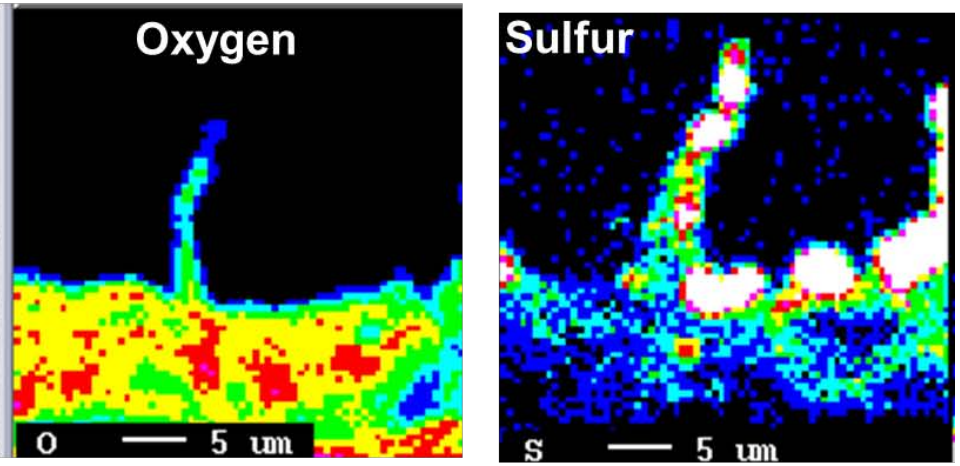

High Magnification Cross-Section Image and STEM Elemental Maps
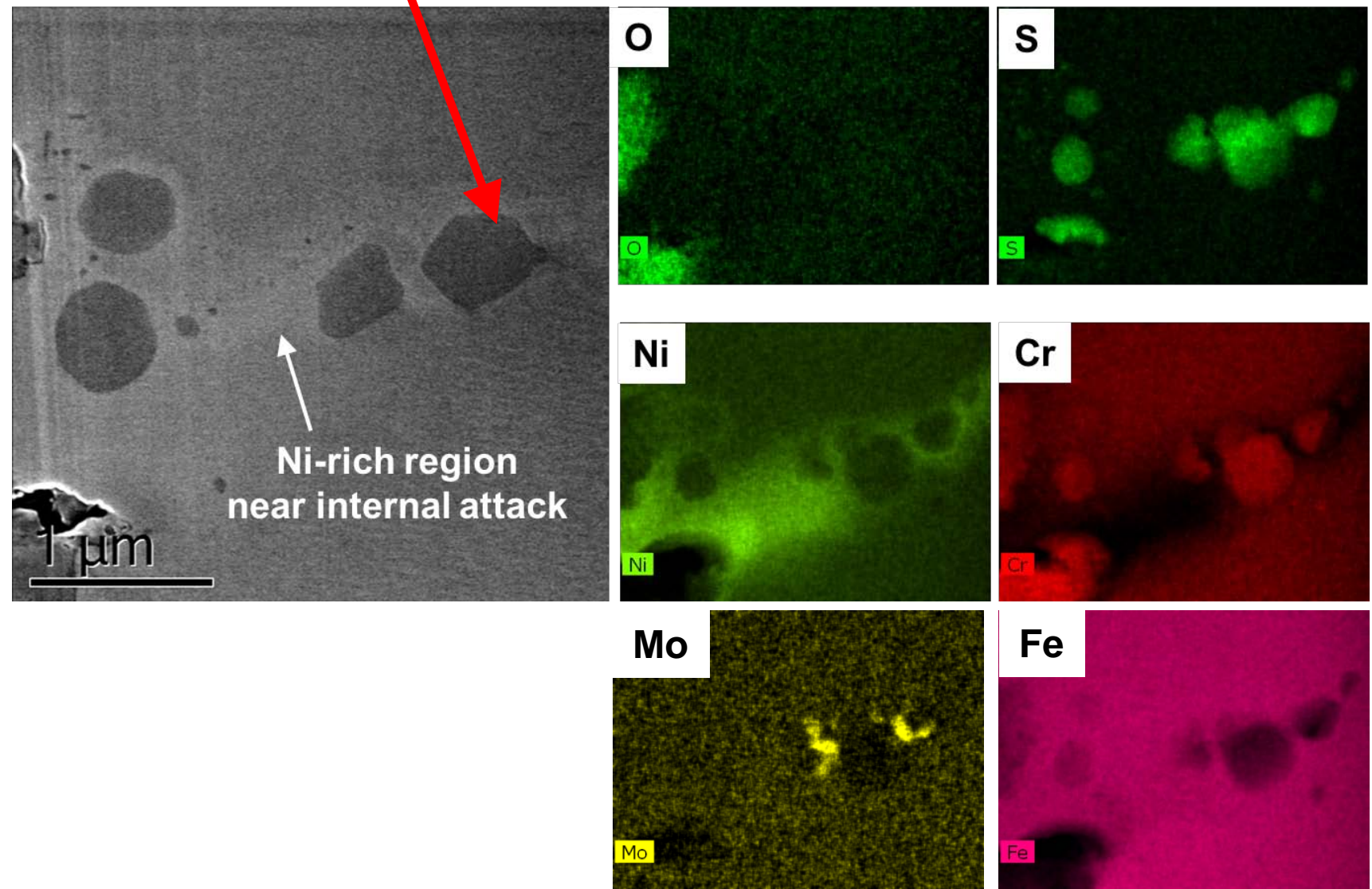

\section{$\mathrm{Fe}$}

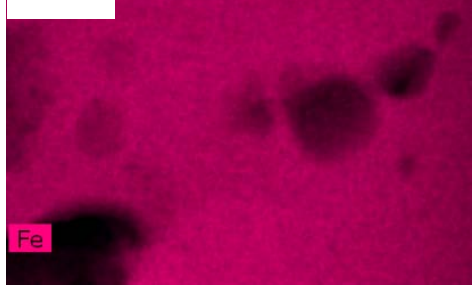

Figure 13 - Cross-section analysis of a 316L pyrolyzer tube after $>2000$ h operation in a biomass pyrolysis system. Cross-section SEM and microprobe images after reference 44. STEM analysis of internal grain boundary attack region shows local Ni-enriched region containing Cr-S nanoparticles at tip of the reaction front. Each individual element map is raw counts and plotted as an intensity scale. Black is no signal and higher intensities signify higher counts and therefore higher amounts of the element is present in that pixel. 